\title{
Stochastic Computer Simulation of Cermet Coatings Formation
}

\author{
Oleg P. Solonenko, ${ }^{1}$ Vladimir I. Jordan, ${ }^{2}$ and Vitaly A. Blednov ${ }^{1}$ \\ ${ }^{1}$ Khristianovich Institute of Theoretical and Applied Mechanics, Siberian Branch of RAS, 4/1 Institutskaya Street, \\ Novosibirsk 630090, Russia \\ ${ }^{2}$ Altai State University, 61 Lenin Avenue, Barnaul 656049, Russia
}

Correspondence should be addressed to Vladimir I. Jordan; jordan@phys.asu.ru

Received 19 January 2015; Revised 14 July 2015; Accepted 16 July 2015

Academic Editor: Belal F. Yousif

Copyright (C) 2015 Oleg P. Solonenko et al. This is an open access article distributed under the Creative Commons Attribution License, which permits unrestricted use, distribution, and reproduction in any medium, provided the original work is properly cited.

\begin{abstract}
An approach to the modeling of the process of the formation of thermal coatings lamellar structure, including plasma coatings, at the spraying of cermet powders is proposed. The approach based on the theoretical fundamentals developed which could be used for rapid and sufficiently accurate prediction of thickness and diameter of cermet splats as well as temperature at interface "flattening quasi-liquid cermet particle-substrate" depending on the key physical parameters (KPPs): temperature, velocity and size of particle, substrate temperature, and concentration of finely dispersed solid inclusions uniformly distributed in liquid metal binder. The results are presented, which concern the development of the computational algorithm and the program complex for modeling the process of laying the splats in the coating with regard to the topology of its surface, which varies dynamically at the spraying, as well as the formation of lamellar structure and porosity of the coating. The results of numerical experiments are presented through the example of thermal spraying the cermet TiC-30 vol.\% NiCr powder, illustrating the performance of the developed computational technology.
\end{abstract}

\section{Introduction}

In the advanced technologies of thermal (including plasma) spraying, there is in most cases no possibility of in-process control of coating quality. This circumstance greatly impedes the coating design and optimization. To the knowledge of the present authors, until now there is no concept that is physically grounded and approved in practice, which would allow approaching the design and optimization of specific technologies of thermal spraying (the plasma, flame, detonation spraying, metallization, etc.) from the unified standpoint. The spraying process improvement is usually realized by conducting a limited set of technological experiments on a specific facility using the powder material of this or that fraction composition with subsequent studying of the characteristics of sprayed coatings. Taking into account a fairly large number of factors determining the result of the spraying process, the "trial and error" method is completed in a number of cases by planning an experiment, diagnostics, or/and modeling of the in-flight particles characteristics in high-temperature jet and prior to impact onto the base surface. The attempts of performance of end-to-end complex experiments in thermal spraying for the purpose of studying the physical processes, occurring in the chain "generation of high-temperature flow-powder material injection-formation of technological dusted flow-splats and coating formation," are not numerous and mainly of a methodological interest because of their high labor efforts at development of specific technology.

Thermal and, in particular, plasma spraying of nano- or submicrometer structured cermet coatings made of composite powders with decamicrometer size particles containing ultrafine inclusions of a very hard chemical compound dispersed in a metal alloy matrix ( $\mathrm{TiC}-\mathrm{NiCr}$, WC-Co, $\mathrm{Cr}_{3} \mathrm{C}_{2}-\mathrm{NiCr}, \mathrm{TiB}_{2}-\mathrm{Cu}$, etc.) opens up vast possibilities in the formation of wear-, abrasive-, and corrosion-proof coatings intended for use under severe operation conditions. The high carbide phase content in cermet powder particles (5070 vol.\% and more) makes the melted metal binder, containing hard, finely dispersed suspended inclusions, highly viscous $[1,2]$. Among other things, the high viscosity of sprayed quasi-liquid "melted binder-ultrafine solid inclusions" 


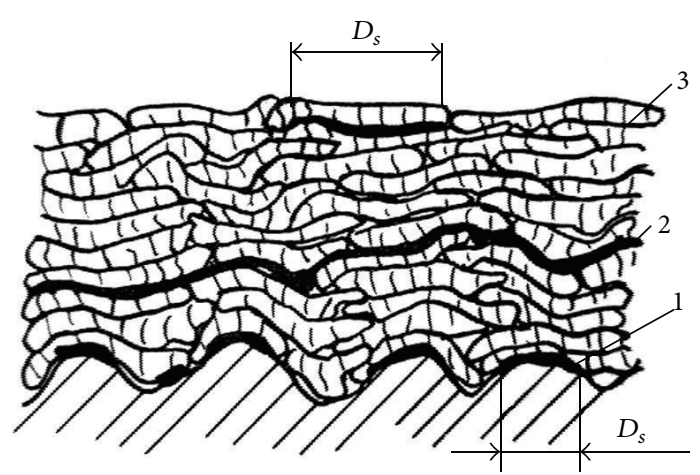

FIGURE 1: Schematic representation of the lamellar structure of plasma coating formed from the particles on a rough substrate. 1: the interface between the coating and the base, 2: the interface between the sprayed layers, and 3: the interface between the splats.

particles provides a low degree of their deformation at impact with substrate or previously sprayed coating layer [1]. That is why the plasma-sprayed cermet coatings normally have comparatively high macroporosity formed at the junctions between individual splats (spread and solidified particles) and at the coating-substrate interface. In this regard, development of scientific bases and computational technology, which would allow carrying out preliminary computing experiments for formulation of requirements to the key physical parameters (KPPs) characterizing the coating formation in cross-section of spraying spot, seems to be highly topical.

For the prediction of the structure and properties of the sprayed coating in the technological chain "plasma torch-jetcermet coating," the main attention in the following will be paid to the modeling of its lamellar structure (Figure 1). It is formed from cermet particles consisting of fully melted metal binder and solid ultrafine refractory inclusions uniformly distributed within the binder.

As is known [3], at plasma spraying, even at the maximum possible loading of jet by the powder material whose particles are to complete melting, the coating is formed by a layer-bylayer deposition of individual splats, that is, the melt droplets spread and solidified on the base (substrate or preliminary sprayed layer). Consequently, the reliability of the results of modeling the structure of the sprayed coating is determined, generally speaking, mainly by the accuracy of the computation of the individual splats formation under the given values of the KPPs prior to collision of particle with the base.

For evaluating the required computing costs, let us assume that it is necessary to conduct the modeling of the process of the coating fragment formation with transverse sizes $L_{x}$ and $L_{y}$ of thickness $h$, and the sprayed powder is assumed to be monodisperse with the particle size $D_{p}$. Thus, if the volume of pores in the coating is neglected, in a first approximation, then the estimate of the necessary amount of splats for complete filling of the coating volume $V=L_{x} L_{y} h$ will be presented as $N_{p}=6 V /\left(\pi D_{p}^{3}\right)=6 L_{x} L_{y} h /\left(\pi D_{p}^{3}\right)$. That is, if the coating fragment has the base area $S=1 \mathrm{~cm}^{2}$ $\left(L_{x}=L_{y}=1 \mathrm{~cm}\right)$ and the thickness $h=100 \mu \mathrm{m}$, then at the size of sprayed particles $D_{p}=10,25,50$, and $100 \mu \mathrm{m}$ it is necessary to carry out the modeling of the process of splats formation at the amount of $N_{p} \approx 1.9 \cdot 10^{7}, 1.2 \cdot 10^{6}, 1.5 \cdot 10^{5}$, and $2 \cdot 10^{4}$, respectively. Detailed modeling of the process of a single splat formation generally requires the computation of three- or two-dimensional unsteady boundary-value problems with a free boundary for the Navier-Stokes equations together with the equations of the conjugate convectiveconductive heat transfer as well as phase transitions in the spreading particle and in a number of cases also in the substrate [4-14] and so forth. If it is assumed that one second of the processor time is required for such computation of single splat formation, which is a quantity underestimated considerably by at least one-two orders (even at the modeling of the process of splat formation on a smooth substrate), then the computing time will amount, respectively, to $t_{\text {calc }} \approx 5280$, 336,48 , and 5.5 hours. That is why today the latter approach presents an independent theoretical rather than practical interest as modeling of several dozens or hundred thousand droplets interacting with the substrate or with the previously deposited coating layer will entail huge computational costs.

An alternative to it is the use of experimentally validated theoretical solutions or semiempirical dependencies, allowing us to predict with an accuracy sufficient for practice the thickness and diameter of splats in some range of the KPPs, which accelerates substantially (by several orders of magnitude) the computational procedure of modeling the lamellar structure of coatings [15-28].

As it was noted in paper [2], presently, a number of publications are available whose authors make attempt of theoretical and experimental generalization of splat diameters in thermal spraying of powder materials [29-43]. In these publications, authors use a dimensionless representation of splat diameter, $\bar{D}_{s}=D_{s} / D_{p}$, or spreading factor, in the form $\bar{D}_{s}=a \operatorname{Re}^{\alpha} \mathrm{We}^{\beta}$. Then, on the assumption of a cylindrical (disk) shape of the splat and with due account of the balance of particle volume prior to and after the impact, the nondimensional splat thickness $\bar{h}_{s}=h_{s} / D_{p}$ can be represented with the dependence $\bar{h}_{s}=\left(2 / 3 a^{2}\right) \cdot \operatorname{Re}^{-2 \alpha} \mathrm{We}^{-2 \beta}$. A fundamental drawback of these dependences is that all of them do not take into account all KPPs and ignore the difference between hydrodynamic and thermophysical features of metallic and ceramic splats formation process. For instance, testing reported dependences in a wide range of dropletsubstrate interaction parameters performed using a representative set of experimental metal splats (more than 600) obtained under full control of KPPs of the process (velocity, temperature, and size of droplet; temperature of polished substrate) [44, 45] have shown their quite limited appropriateness in predicting the metallic splat characteristics.

The peculiarities of metal and metal oxide splats formation from melted particles impacting on substrate under thermal spraying conditions were examined and analyzed in several recently published reviews [45-54]. The authors have considered and discussed the effects due to the most important factors governing the splat formation process: roughness and temperature of substrate, properties of splat-substrate 
interface, contact temperature, thermal resistance between the flattening droplet and substrate, surface chemistry and wettability, cooling rate of droplet, droplet material splashing, formation of oxide layer, and so forth.

At the same time, as far as we know, until our publications $[2,55]$ there were no published papers devoted to theoretical study of the formation process of individual cermet splats, deposited on a substrate under full control of KPPs, including the particle size, the particle velocity, the particle temperature, and the base (substrate) temperature, with the free parameter being the volume concentration of ceramic (carbide, oxide, nitride, etc.) inclusions in the metal binder. The approximate solutions proposed in $[56,57]$ do not solve completely the above problem from technological point of view, because the derived solutions do not take into account the full set of KPPs defining the thickness and diameter of splats as well as the "particle-base" contact temperature.

In the present paper, an approach is proposed to the modeling of a lamellar structure formation process of thermal coatings, including plasma coatings, at the spraying of cermet powders. The results are presented, which concern the further development of the computational algorithm and the program code [28] for modeling the process of laying the cermet splats in the coating with regard to the morphology of its surface, which varies continually at the spraying, as well as the formation of a lamellar structure and porosity of the coating. The theoretical solution [2] is used for rapid prediction of splats thicknesses and diameters as well as contact temperature at "quasi-liquid cermet particle-base" interface depending on the KPPs prior to interaction. The results of computational experiments illustrating the performance of the developed computational technology are presented. This gives rise to a possibility of formulating the requirements for specific thermal spray facility and investigating its potential technological capabilities from the viewpoint of ensuring the given characteristics of the coating.

\section{The Fundamentals of Cermet Splat Formation}

In accordance with $[2,55]$, let us consider that the spreading, heat transfer, and phase transition processes proceed in a spherical composite particle of decamicrometer size $D_{p}$ impinging onto a flat substrate. The particle consists of a melted metal binder and ultrafine refractory solid inclusions uniformly distributed in the binder and in doing so each inclusion has a characteristic size $d_{p} \ll D_{p}$. Let us assume that $u_{p 0}$ and $T_{p 0}$ are the velocity and the temperature of the particle, respectively, at the moment the particle impacts on the solid substrate, whose temperature is $T_{b 0}<T_{p 0}$. Since the metal binder in the particle is in a molten state while the refractory inclusions are solid, we assume that $T_{1 m} \leq$ $T_{p 0}<T_{2 m}$, where $T_{1 m}$ and $T_{2 m}$ are the melting point of the binder and the melting point of the solid inclusions, respectively. Next, we assume that $s$ is a volume concentration of solid inclusions in two-phase composite particle "melted metal binder-solid inclusions," so that a volume fraction of the metal binder in the heterogeneous material is $(1-s)$.
In this manner, $L_{p m}(s)=(1-s) L_{1 m}$ is the effective latent heat of binder per unit volume of heterogeneous material. Like in $[2,55]$, we introduce in our consideration the effective density $\rho_{p}$, the effective specific heat $c_{p}$, and the effective thermal conductivity $\lambda_{p}$ of the cermet particle material. According to the additivity concept, those quantities can be represented as

$$
\begin{gathered}
\rho_{p}(s)=(1-s) \rho_{1}+s \rho_{2}, \\
c_{p}(s)=(1-s) c_{1}+s c_{2}, \\
\lambda_{p}(s)=(1-s) \lambda_{1}+s \lambda_{2} .
\end{gathered}
$$

Subscripts $j=1$ and 2 correspond to metal binder and carbide inclusions, while subscripts " $p$ " and " $b$ " correspond to cermet particle and base (substrate), and superscripts " $s$ " and "l" correspond to solid and liquid state of binder. We assume that, as the metal binder inside the particle undergoes melting and overheating, the carbide inclusions remain solid and indissoluble in the case under study.

Thus, we have evaluated all the required thermophysical characteristics of the heterogeneous material. Those characteristics parametrically depend on the volume concentration $s$ of high-melting solid inclusions, which is the parameter to be set a priori.

Let us consider the most widely spread case at thermal spraying when formation of splats is occurring under conditions of spreading and simultaneous solidification of quasiliquid particle on solid substrate.

In accordance with [2], at given values of KPPs and at given volume content of refractory ultrafine solid inclusions uniformly distributed in a liquid metal binder, the nondimensional thickness $\bar{h}_{s}=h_{s} / D_{p}$ of the cermet splat in the vicinity of stagnation point $\left(2 r<k_{1} D_{p}\right.$, where $\left.k_{1} \sim 1\right)$ can be calculated using the following approximate formula:

$$
\begin{array}{r}
\bar{h}_{s}=\sqrt[3]{\frac{c_{\zeta}^{2}}{2 \mathrm{Pe}} \cdot[\sqrt[3]{\sqrt{1+\kappa}+1}-\sqrt[3]{\sqrt{1+\kappa}-1}]}, \\
\kappa=\frac{4 c_{\zeta}^{2}}{27 \mathrm{Pe}} .
\end{array}
$$

The nondimensional diameter $\bar{D}_{s}$ of splat in the case of its disk shape can be determined from the balance of particle volume prior to and after the impact on substrate. The calculation yields

$$
\bar{D}_{s}=\sqrt{\frac{2}{\left(3 \bar{h}_{s}\right)}} .
$$

For sufficiently small values of the parameter $\kappa$, the expression in the square brackets of (2) can be replaced with $\sqrt[3]{2}$. As a result, expression (2) is reduced to

$$
\bar{h}_{s}=\sqrt[3]{\frac{c_{\zeta}^{2}}{\mathrm{Pe}}} .
$$

For instance, for $\kappa=10^{-2}, 10^{-3}$, and $10^{-4}$, the relative approximation inaccuracy $\varepsilon$ of expression (4) with expression 
(2) is, respectively, $\varepsilon \approx 13,6$, and $3 \%$. As a rule, at thermal spraying, in particular, plasma spraying we have Pe $>1000$ and $c_{\zeta}<2$. In the latter case, the relative inaccuracy $\varepsilon$ is well within $5 \%$. The latter allows using expression (4) in practical calculations. On substitution of (4) into the dependence (3), we obtain the following simple formula for nondimensional splat diameter:

$$
\bar{D}_{s}=\sqrt{\frac{2}{3}} \sqrt[6]{\frac{\mathrm{Pe}}{c_{\zeta}^{2}}} .
$$

The following parameters are used in (2)-(5): Pe = $D_{p} u_{p 0} / a_{p m}^{(l)}$ is the Péclet number, $a_{p m}^{(l)}=\lambda_{p m}^{(l)} / \rho_{p m}^{(l)} c_{p m}^{(l)}$ is the thermal diffusivity of the particle heterogeneous material at melting point of binder, and $c_{\zeta}$ is parameter characterizing the rate of the cermet quasi-liquid particle solidification calculated in accordance with [2]

$$
\begin{aligned}
& c_{\zeta}=\frac{p\left[\sqrt{1+4 q / p^{2}}-1\right]}{2}, \\
& p=\frac{\pi \lambda_{p, p}^{(s, l)}+2 K_{\varepsilon}^{(b, p)} \operatorname{Ste}_{p}^{(l)}\left(\vartheta_{p 0}-1\right)}{\sqrt{\pi} K_{\varepsilon}^{(b, p)}}, \\
& q=2 \lambda_{p, p}^{(s, l)} \operatorname{Ste}_{p}^{(l)}\left(1-\vartheta_{b 0}\right) \cdot\left[1-\frac{\vartheta_{p 0}-1}{\left(1-\vartheta_{b 0}\right) K_{\varepsilon}^{(b, p)}}\right],
\end{aligned}
$$

where $K_{\varepsilon}^{(b, p)}=\sqrt{(\rho c \lambda)_{b 0}^{(s)} /(\rho c \lambda)_{p m}^{(l)}}$ is the relative thermal effusivity of substrate (base) material with respect to particle material; $\operatorname{Ste}_{p}^{(l)}=\chi c_{p m}^{(l)} T_{1 m} / L_{p m}(s)$ is the criterion of phase transition of metal binder in heterogeneous material (an analogue of Stefan number for homogeneous material); $\chi=\rho_{p m}^{(l)} / \rho_{1 m}^{(l)}$; subscript " $m$ " characterizes parameters at the melting point of corresponding materials and subscript $s$ in (2)-(5) corresponds to the splat parameters; $\lambda_{p, p}^{(s, l)}=\lambda_{p m}^{(s)} / \lambda_{p m}^{(l)}$; $\vartheta_{p 0}=T_{p 0} / T_{1 m} ; \vartheta_{b 0}=T_{b 0} / T_{1 m}$; and nondimensional contact temperature at the particle-base interface is calculated as

$$
\vartheta_{c}=\frac{1+c_{\zeta} K_{\varepsilon}^{(b, p)} \vartheta_{b 0} / \sqrt{\pi} \lambda_{p, p}^{(s, l)}}{1+c_{\zeta} K_{\varepsilon}^{(b, p)} / \sqrt{\pi} \lambda_{p, p}^{(s, l)}} .
$$

The physical model for the developed process of interest is based on the following assumptions:

(1) The splat formation process proceeds in one stage, and the thickness $h_{s}$ of the formed splat in the vicinity of stagnation point $\left(2 r \leq \kappa D_{p}, \kappa \sim 1\right)$ is defined by the time Fo $=$ Fo $^{*}$, at which the vertex of the inertially spreading viscous melt droplet meets the solidification front $\zeta=\zeta($ Fo $)$ (Figure 2), Fo $=a_{p m}^{(l)} t / D_{p}^{2}$ is Fourier number. This case is encountered in the impingement of decamicrometer particle with melted metal binder and with a high concentration of solid inclusions.

(2) We assume that, at the moment the quasi-liquid particle impacts on the base, a velocity field of the viscous flow is established throughout the entire volume of the particle,

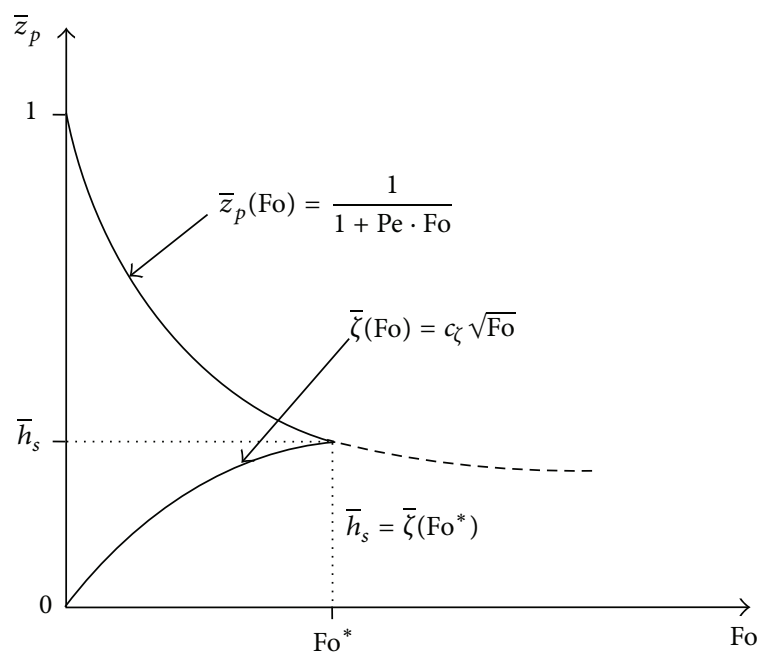

FIGURE 2: Hydrodynamic and thermophysical feature of the cermet splat formation process.

typical for viscous flow in the vicinity of stagnation point with normal and radial velocity components [58] $u_{z}=-\beta z^{2}$ and $u_{r}=\beta z r$, where $\beta=u_{p 0} / D_{p}^{2}$. Then, the particle undergoes inertial spreading. The current coordinate $z_{p}=z_{p}(t)$ of the particle vertex can be determined from the following equation $d z_{p} / d t=-\beta z_{p}^{2}$, which acquires the form $d \bar{z}_{p} / d$ Fo $=$ $-\mathrm{Pe} \cdot \bar{z}_{p}^{2}, \bar{z}_{p}=z_{p} / D_{p}$. On integration of the latter equation with the initial condition $\bar{z}_{p}(0)=1$, we obtain the following solution of the Cauchy problem for the current coordinate of the particle vertex in the deformation process: $\bar{z}_{p}(\mathrm{Fo})=$ $1 /(1+\mathrm{Pe} \cdot \mathrm{Fo})$.

(3) No metallic melt overcooling occurs below its melting point $T_{1 m}$, that is, the droplet solidifies under equilibrium conditions.

(4) All thermophysical properties of the binder, carbide inclusions, and substrate materials are temperatureindependent. The properties of composite particle are taken at melting point $(m)$ of binder for solid $(s)$ and liquid $(l)$ state, while the properties of substrate are taken at temperature $T_{b 0}$.

(5) At the particle-base interface, a perfect contact between the two materials is realized. A fundamental feature of the developed theoretical approach is that, with the help of the solution obtained, one can predict the splat thickness in the vicinity of stagnation point $\left(2 r \leq \kappa D_{p}, \kappa \sim 1\right)$. In this case, both the assumption of one-dimensionality of the nonstationary conjugate heat transfer and phase transition processes in the particle-substrate system and the assumption of a perfect contact at the stage of pressure spreading of the melt can be considered well substantiated.

(6) The substrate is a semi-infinite body. It can be shown that, during the whole splat formation process, the depth to which thermal disturbance penetrates the substrate is smaller than particle diameter.

(7) During two-phase particle spreading and solidification, the effective contact temperature at the interface between the solidifying layer and substrate, calculated in 
accordance with (7), remains unchanged and satisfies the conditions $T_{c}<T_{1 m}$ and $T_{c}<T_{b m}$.

(8) We assume that the temperature distribution across the solidifying layer is always quasi-stationary; that is, the temperature across the solidifying layer varies linearly from $T_{c}$ to $T_{1 m}$.

(9) Due to high volume content of solid refractory inclusions in the volume of composite quasi-liquid particle (50-70\% and more) and extremely high viscosity, a surface tension does not play a considerable role in the stage of the splat formation process.

(10) In determining the splat thickness $h_{s}$ in the vicinity of the stagnation point $\left(2 r \leq \kappa D_{p}, \kappa \sim 1\right)$, we assume all nonstationary conjugate heat transfer processes in the particle-substrate system, including phase transitions, to be one-dimensional ones. In this formulation, the splat thickness $h_{s}$ is more rigidly related to the KPPs of the process and to the thermophysical properties of the particle and substrate materials. This thickness turns out to be almost independent of the peripheral processes in the spreading particle. Having determined the splat thickness, we may determine the splat diameter using the balance relation for the particle volume prior to and after the impact and assuming the final shape of the splat to be almost cylindrical.

(11) Since metal melts (nickel, cobalt, etc.) readily wet titanium, tungsten, boron, silicon, or chromium carbides [59], it can be assumed that, during the solidification of metal binder, the solidification front moving in the binder induces no displacement of ultrafine ceramic inclusions inside the particle. Hence, the heterogeneous medium "binder meltsolid inclusions" can be treated as a two-phase quasi liquid. The authors of [57] experimentally found that the large solid carbide particles in a two-phase droplet tend to rebound easily under HVOF spraying when the droplet impacts on a substrate surface, while small carbide particles $\left(d_{p} \sim 1 \mu \mathrm{m}\right.$ and less) in the droplet may follow the spreading liquid binder and be easily retained in the deposit.

\section{Structure and Possibilities of Software Developed}

The developed software "SPLAT-COATING" includes two subsystems (Figure 3). The first one, "SPLAT," on the basis of restrictions imposed on splat parameters, calculates and produces $3 \mathrm{D}$ visualization of the physically realizable subspaces of the initial space of the KPPs. The second one, "COATING," on the basis of KPPs values calculated from the given histograms, characterizing the distributions of size, velocity, and temperature of sprayed particles for sufficiently small area (cluster) of a deposited coating, with the use of reference data on the physical properties of materials, performs the stochastic computer simulation and subsequent visualization of the lamellar structure and functional characteristics of the coating deposited.

Subsystem "SPLAT." According to [44], the droplet-base interaction process, in the stage of pressure spreading, generally follows one of the four basic scenarios (Figure 4): (1) spreading and simultaneous solidification of the droplet

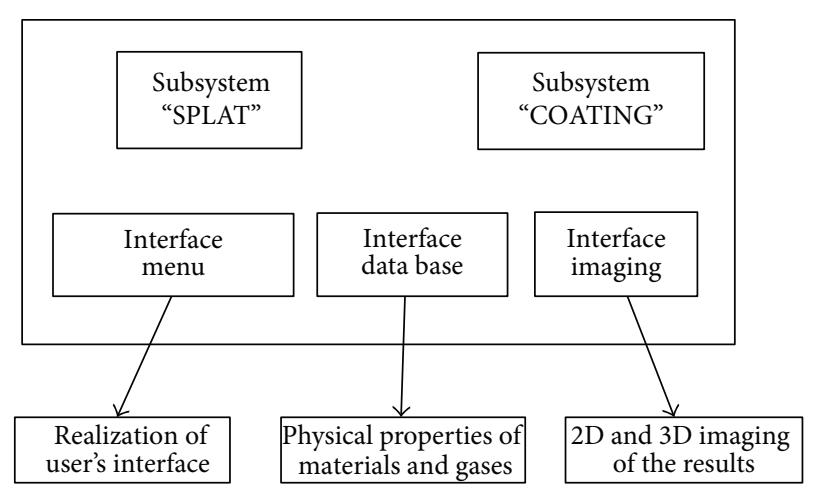

FIGURE 3: Structural block diagram of program complex developed.

on the solid surface followed by subsequent cooling of the formed splat; (2) spreading and simultaneous solidification of the droplet with partial submelting of the substrate in the contact spot of the particle with the substrate, followed by subsequent solidification of the melted substrate layer and cooling of the splat-base system; (3) complete spreading of the droplet on the solid base followed by subsequent cooling and solidification of the spread melt layer; (4) complete spreading of the droplet with simultaneous partial submelting of the base, followed by subsequent cooling and solidification of the spread droplet and the near-surface melted layer in the base.

When forming cermet splats as melting point of quasiliquid particle, we understand melting temperature of metal binder; that is, $T_{p m}=T_{1 m}$. Temperature of contact $T_{c 0}$ is calculated according to formula $T_{c 0}=\left[T_{p 0}+\right.$ $\left.K_{\varepsilon}^{(b, p)} T_{b 0}\right] /\left[1+K_{\varepsilon}^{(b, p)}\right]$ where the coefficient of the relative effusion $K_{\varepsilon}^{(b, p)}$ is calculated in accordance with formula $K_{\varepsilon}^{(b, p)}=\sqrt{(\rho c \lambda)_{b 0}^{(s)} /(\rho c \lambda)_{p m}^{(l)}}$.

As it was noted above, the main operating principle of the "SPLAT" subsystem consists in sequential truncation of the initial operating space of KPPs on satisfaction of the requirements imposed on the designed splat. The original space of KPPs is a 3D space whose axes are selected by the user from the list of KPPs: $T_{p 0}, T_{b 0}, u_{p 0}$, and $D_{p}$ (or the Péclet number $(\mathrm{Pe})$ instead of $u_{p 0}$ and $\left.D_{p}\right)$. For each of the axes, we set a minimum value and a maximum value of a given parameter that restrict the examined region of the space over this parameter. The restriction is represented with some function or with some inequality that divides the operating space of the KPPs into two regions, a region in which the condition is satisfied and a region in which the condition cannot be met. As a result, we obtain some truncation of the initial KPPs space. The restrictions come as requirements imposed on splat sizes, on the ranges of particle velocities and temperatures, and on the evolution of substrate temperature during droplet spreading. The list of the most important requirements that can be imposed on splat is given in [28]. In particular, the subsystem "SPLAT" allows formulation of restrictions on different parameters, including realization of one of the four basic splat formation scenarios, splat formation duration, and the contact temperature at the particlesubstrate interface with allowance for the set splat formation 


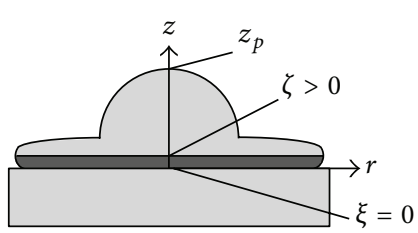

$T_{b m}>T_{c 0}<T_{p m}$

(1)

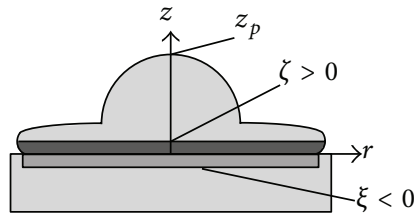

$T_{b m} \leq T_{c 0}<T_{p m}$

(2)

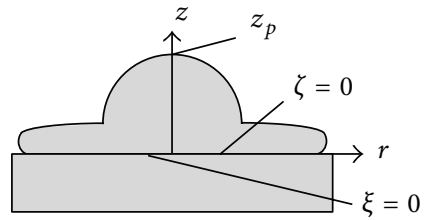

$T_{b m}>T_{c 0} \geq T_{p m}$

(3)

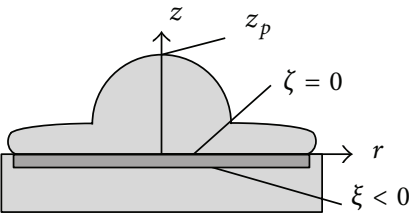

$T_{b m} \leq T_{c 0} \geq T_{p m}$

(4)

FIGURE 4: Qualitative representation of basic scenarios of splats formation at thermal spraying.

scenario. Another group of restrictions involves technological demands and the demand for appropriateness of chosen materials in terms of a bond strength with the substrate or with the already sprayed layer (adhesion and cohesion), the rate of droplet cooling during solidification, and so forth. So formulating, one by one, restrictions to the splat formation process, we obtain a subspace of the initial KPPs space in which all the formulated requirements can be met. If some requirements prove to be contradicting, then the final KPPs set becomes an empty set.

Separate blocks in the subsystem "SPLAT" are modules intended for analyzing the "direct" and "backward" sensitivity "splat thickness $\leftrightarrow$ KPPs value" and for constructing correlation dependences of splat characteristics versus individual KPPs, these dependences being helpful in analyzing qualitative and quantitative regularities of the spray process [60].

The above approximate theoretical solutions for splat thickness and diameter, as well as contact temperature, answering the first splat formation scenarios, which is the most widespread one in the thermal spray technologies, were obtained on the assumption of a perfect contact between the particle, undergoing spreading and solidification, and the base. Due to the high dynamic pressure, this assumption for the melt flow in the vicinity of the stagnation point of the quasi-liquid particle flow $\left(2 r<k_{1} D_{p}, k_{1} \sim 1\right)$ is valid to sufficient accuracy even for rough substrates with roughnesselement heights being smaller than the final splat thickness.

As is seen from the analysis of obtained solutions (2)-(7), the thickness and diameter of cermet splats are determined completely by the Péclet number ( $\mathrm{Pe}$ ), the initial temperatures of the particle $T_{p 0}$ and the substrate $T_{b 0}$, and the thermophysical properties of their materials. Consequently, if one specifies the ranges of the potential variation of the KPPs, then the rectangular parallelepiped

$$
\begin{aligned}
& \Phi_{0} \\
& =\left\{\frac{\left(\mathrm{Pe}, T_{p 0}, T_{b 0}\right)}{\left[\mathrm{Pe}_{\min } ; \mathrm{Pe}_{\max }\right] \times\left[T_{p, \text { min }} ; T_{p, \text { max }}\right] \times\left[T_{b, \text { min }} ; T_{b, \text { max }}\right]}\right\}
\end{aligned}
$$

will be the original KPPs space for a fixed pair of the materials "particle-base."

For illustration, the following conditions are accepted: the particle material is $\mathrm{TiC}-30 \mathrm{vol} . \% \mathrm{NiCr}$, the substrate material is steel St. $45, D_{p, \min }=20 \mu \mathrm{m}, D_{p, \max }=80 \mu \mathrm{m}, u_{p, \min }=$ $100 \mathrm{~m} / \mathrm{s}, u_{p, \max }=700 \mathrm{~m} / \mathrm{s}, T_{p, \text { min }}=1663 \mathrm{~K}$ (melting point of nichrome), $T_{p, \max }=3433 \mathrm{~K}$ (melting point of titanium carbide), $T_{b, \min }=300 \mathrm{~K}$, and $T_{b, \max }=800 \mathrm{~K}$. The subspaces of the original space $\Phi_{0}$, which correspond to different scenarios of splats formation, are presented in Figure 5 (scenarios 1 (a), 2 (b), 3 (c), and 4 (d) (scenarios 2 is the empty sets)).

Carrying out further design of TiC-30 vol.\% NiCr splats which are formed on steel substrate according to scenario 1 , we find part of subspace (Figure 5(a)), answering to KPPs for which the relative thickness of splats meets the condition $\bar{h}_{s} \leq$ 0.07 .

The obtained truncated subset of KPPs is presented in Figure 6(a). Let us demand further that temperature in contact "splat-substrate" meets condition $T_{c} \geq 1600 \mathrm{~K}$. As a result, we obtain the truncated subspace of KPPs presented in Figure 6(b). And, at last, we will demand that the relative bond strength $\bar{\sigma}[3,45]$ of splats with steel substrate meets an additional condition $\bar{\sigma} \geq 0.8$. As a result we will obtain required set of KPPs (Figure 6(c)), satisfying to all formulated requirements to splats.

It should be noted that, in the course of coating spraying, after formation of several of its monolayers, formation of splats happens on the base whose material is the material of coating, that is, $\mathrm{TiC}-30$ vol. $\% \mathrm{NiCr}$. If in this case the initial space of KPPs is space $\Phi_{0}$ defined above, then, considering change of material of substrate, we will obtain other subdivisions of the operation room of the KPPs corresponding to different scenarios. The example given above demonstrates importance of stage of preliminary analysis and splats design before coatings spraying.

The Subsystem "COATING." The subsystem "COATING" numerically simulates the coating formation process by modeling the stochastic layer-by-layer deposition of splats onto the base, that is, onto the substrate or onto the previously deposited coating, at normal impingement of individual cermet quasi-liquid particles consisting of melted binder and solid refractory inclusions.

It should be noted that simulation and analysis of the functional characteristics of actual coatings, whose area can be rather substantial, require considerable computation costs. Nonetheless, in modeling a coating we can restrict ourselves to calculating some coating cluster (CC) in the form of a coating fragment shaped as a rectangular parallelepiped whose lower base is a rectangle or a square presenting part of the substrate surface and whose upper face has a certain relief that evolves in the course of the spraying process (Figure 7). 


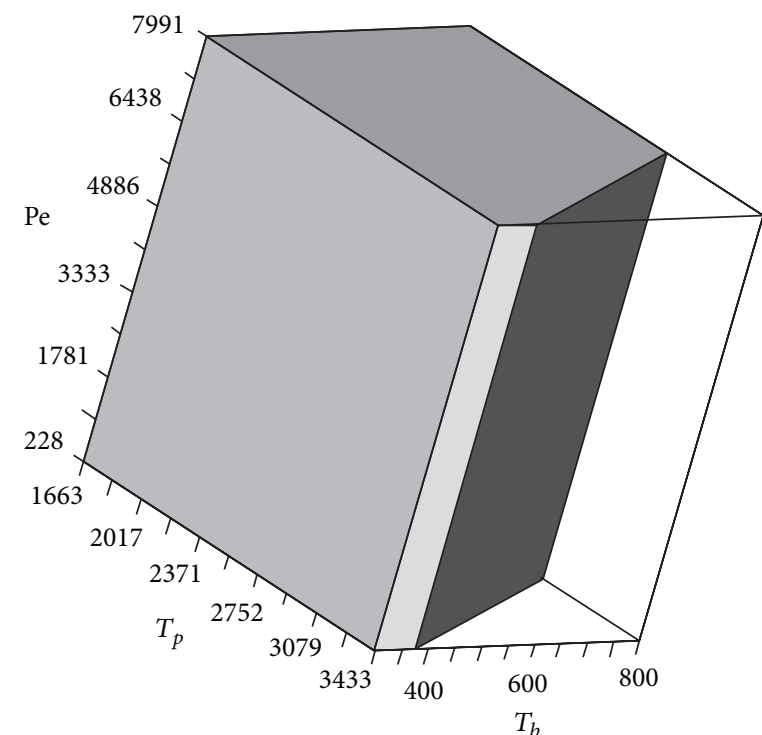

(a)

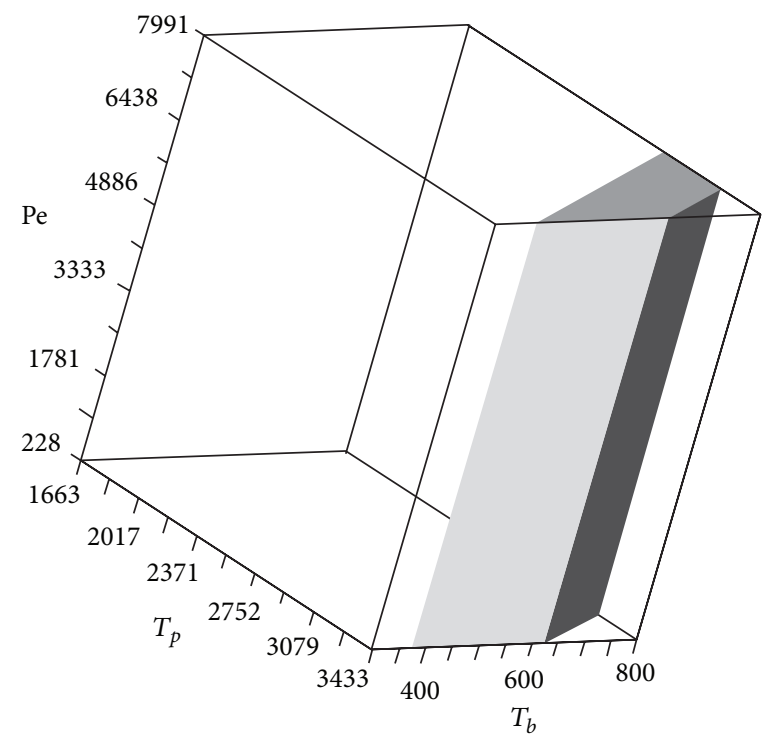

(c)

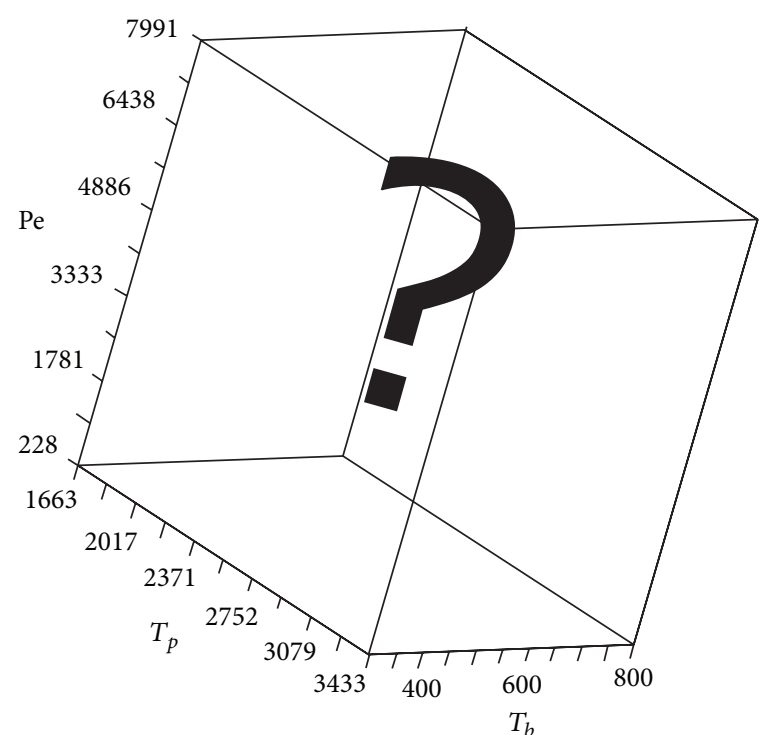

(b)

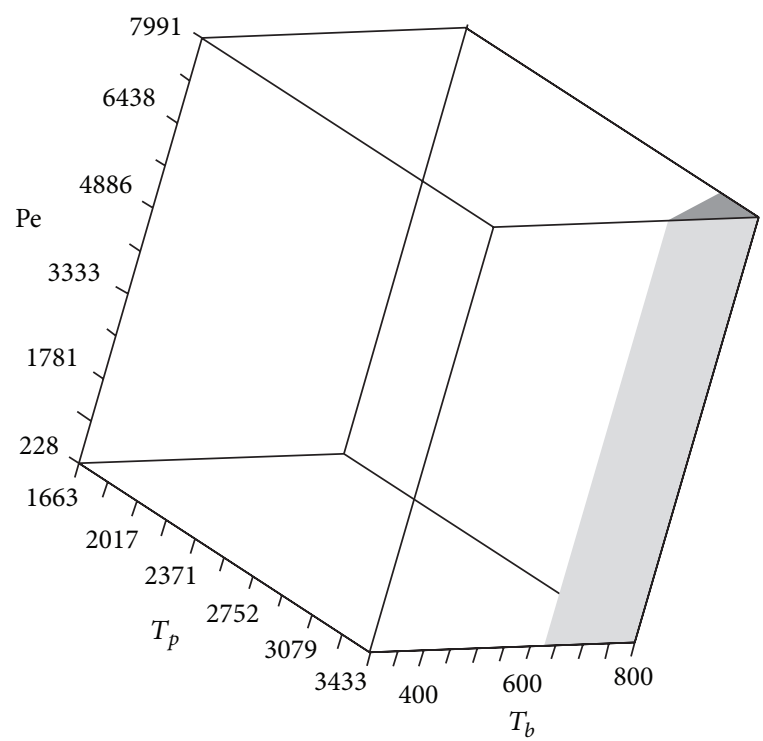

(d)

FIGURE 5: Subspaces of original space of KPPs corresponding to different scenarios of TiC-30 vol.\% NiCr splats formation on steel substrate.

The dimensions of the CC should be chosen so that the modeling of its structure would be close to the structure of a similar coating fragment in modeling the coating as a whole.

In laying the first splat layers, we have to invoke the substrate characteristics (substrate material and substrate temperature) since these parameters, at all other conditions being identical, define the splat formation scenario and also the effective thickness and diameter of formed splats. The type of particle and substrate materials, the KPPs values for the chosen spraying regime, and the values of CC parameters are all to be specified in the user menu, whereas the thermophysical properties of the materials are borrowed from a reference database.

To the spraying process, a certain degree of "stochasticity" is inherent; that is why the characteristics of sprayed particles (size, velocity, and temperature prior to impact with surface of base) within the coating cluster are set complying with their distribution histograms for the particular spraying spot. The histograms are calculated from specified distribution laws for the quantities of interest using quasi-random number generators that generate the surface coordinates of the deposited droplet $x_{p}$ and $y_{p}$; the surface-normal velocity component $u_{p 0}$ of the particle; the particle temperature $T_{p 0}$; and the particle size $D_{p}$. Besides, before the computations, the total number of sprayed particles $N_{p}$, defined by the rate of deposition of the sprayed powder, is to be set.

The particles forming the first coating layer interact with the substrate; that is why in calculating this interaction the main substrate parameters, namely, the properties of substrate material and the substrate temperature $T_{b 0}$, are to 


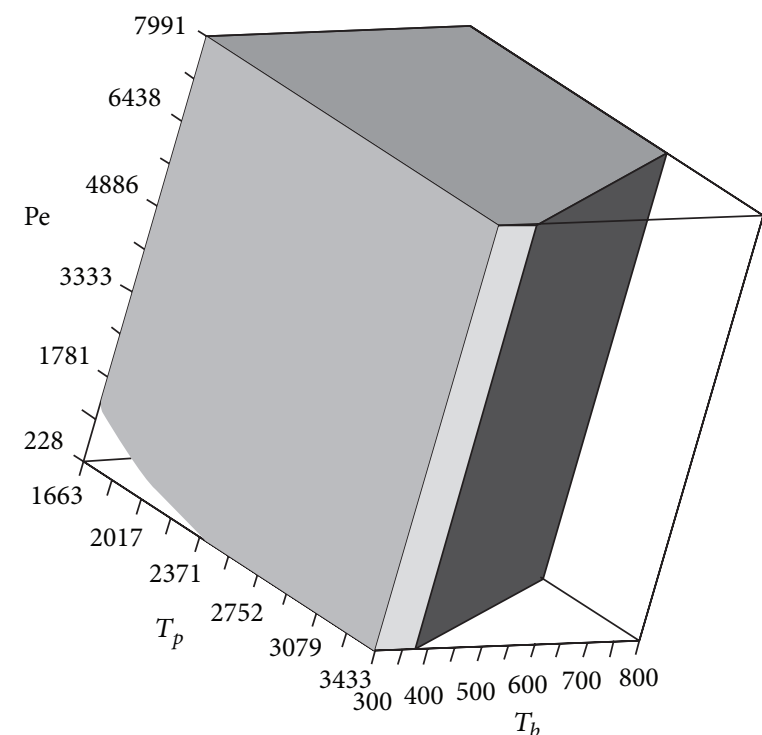

(a)

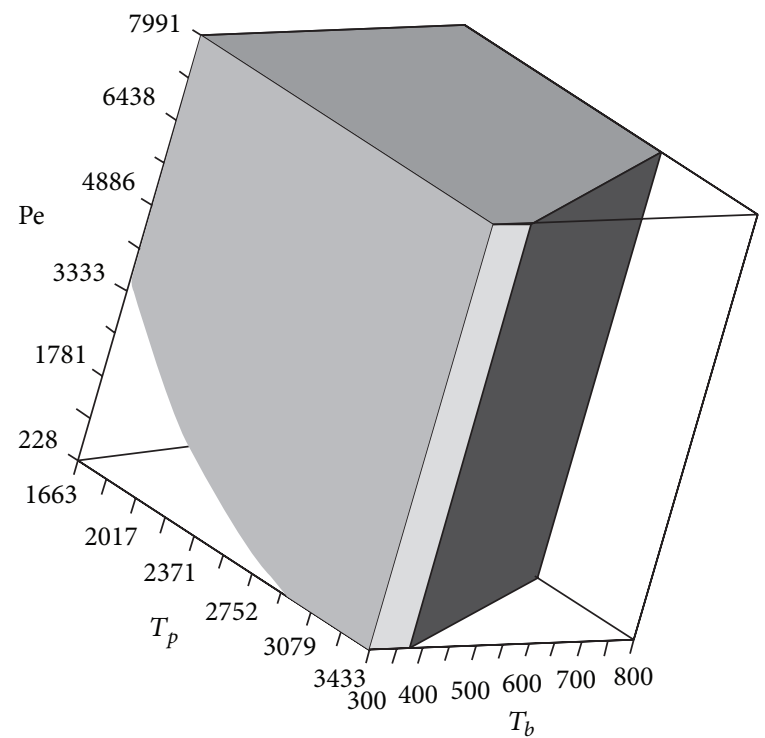

(b)

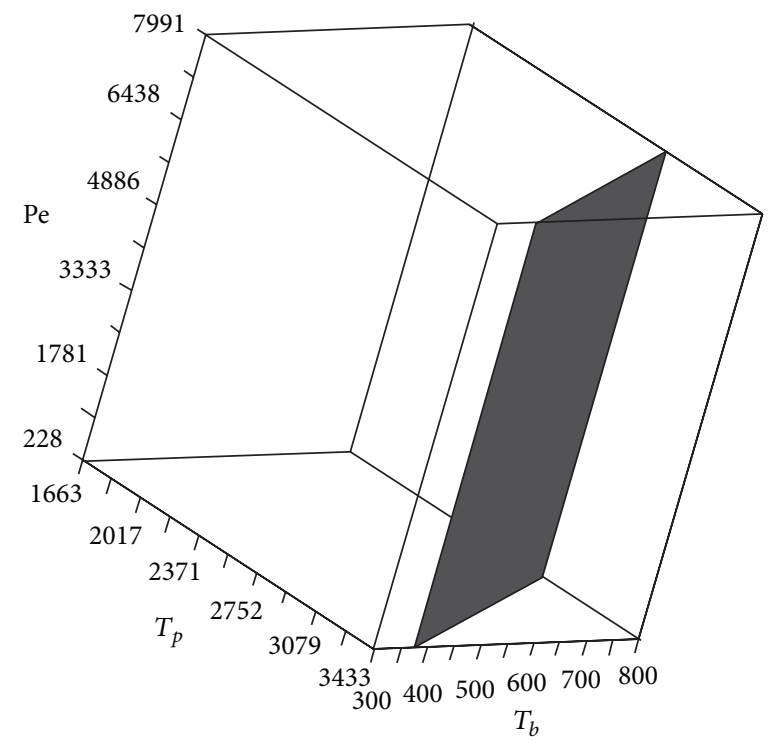

(c)

FIGURE 6: Truncation of subspaces of KPPs answering to the 1st scenario of splats TiC-30 vol.\% NiCr formation on steel substrate, at sequential imposition of restrictions: (a) splats thickness $\bar{h}_{s} \leq 0.07$, (b) temperature in contact $T_{c} \geq 1600 \mathrm{~K}$, and (c) relative bond strength of splats with substrate $\bar{\sigma} \geq 0.8$.

be taken into account. In view of the aforesaid, in the software the splat characteristics (splat thickness $h_{s}$ and splat diameter $D_{s}$ ), whose values have to be determined at each step of the splat-laying algorithm, are calculated using the above theoretical solution (2)-(7), and the laying algorithm itself is described at length in [28].

The developed algorithm for modeling the coating formation rather precisely considers physical features of process of quasi-liquid particles spreading and solidification which, taking into account radial and normal components of velocity of quasi-liquid highly viscous flow in peripheral part of formed splat, allows us to define correctly angle of flowing of melt into the cavities on a surface. Thus, the part of cavity volume that is not filled with spread particle material defines shape of pore which is formed under splat more authentically. The algorithm also allows us to recognize correctly such isolated cavities in a vicinity of stagnation point and in peripheral area of spreading cermet particle which have to be filled with spreading particles material taking into account features of flow in these areas (Figures 8 and 9). And, finally, when developing the numerical algorithm of splats laying, it was required to realize correctly procedure of modifying of initial model shape of splat in the form of thin disk, considering preliminary quasi-liquid filling of recognizable cavities on a surface of base taking into account structure of its roughness, relief of which constantly changes in the course of successive laying of splats. 


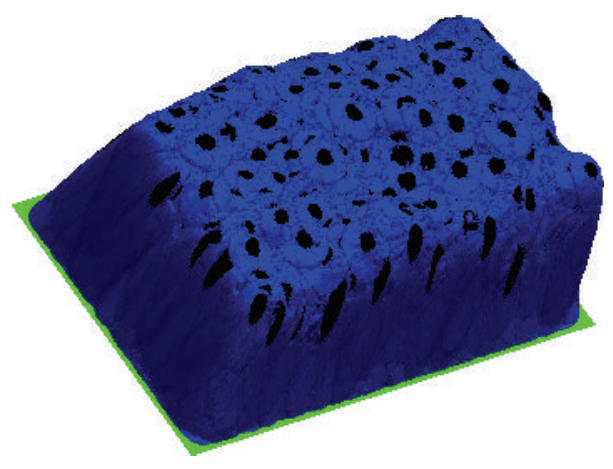

(a)

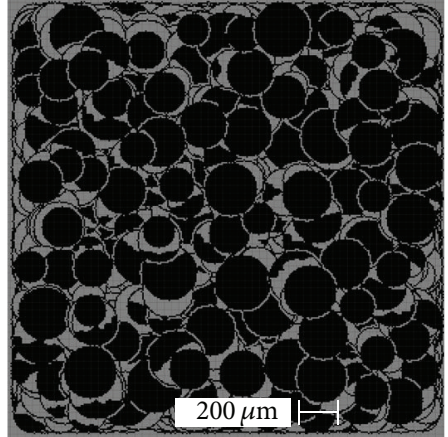

(b)

FIGURE 7: Result of modeling the coating cluster: general view of CC (a), black areas in the coating correspond to core of splats; the view of coating first monolayer from substrate side (b).

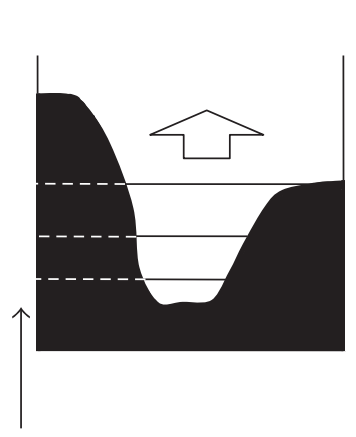

(a)

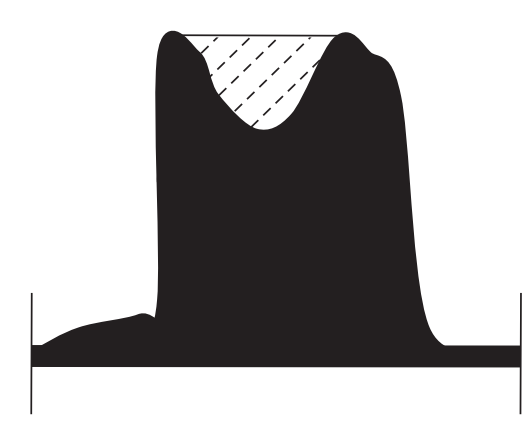

(b)

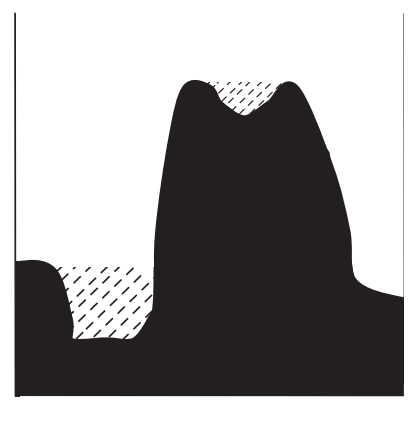

(c)

FIGURE 8: The examples illustrating the cavities on surface of a base and their filling by quasi liquid in zone of contact of splats core with surface: (a) sequential filling of a deep hollow; (b) filling of individual "high-altitude" cavity; (c) simultaneous filling of individual "highaltitude" cavity and "hollow."

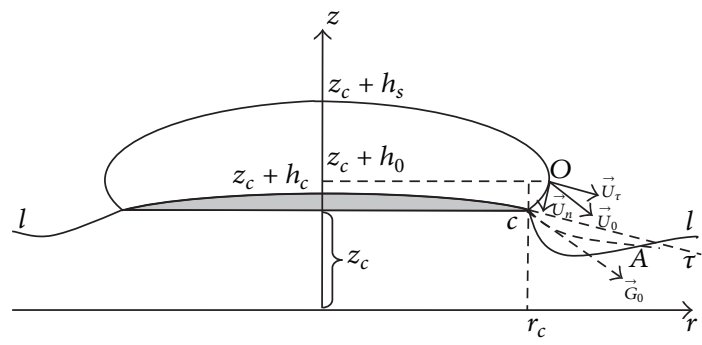

FIGURE 9: Schematic representation of quasi-liquid particle spreading at the moment of flow separation at its meeting with cavity on the base.

With due consideration given to coating surface relief, to be qualitatively reproduced by the deposited splat, in the modeling procedure of the lower and upper splat surfaces we use an approximating tool employing combined "rational B-spline surfaces" [61]. On the basis of datum vertices array $\left\{P_{i, j}\right\}$, whose projection onto the plane $X Y$ forms a $D_{s} \times D_{s}$ square region of the base surface centered at the stagnation point $\left(x_{p}, y_{p}\right)$ of the quasi-liquid particle flow, we construct an approximating surface to be adopted as the lower-base surface of the deposited disk-shaped splat. In order to make the datum-vertex array coordinates adequately taking into account the physical features of the cermet particle solidification process, in the formed splat two zones need to be distinguished: (i) a central zone formed by the splat core and presenting an inner disc, or some vicinity of the stagnation point, of diameter $D_{0}=k_{1} D_{p}$ and thickness $h_{s}$, where $k_{1} \sim 1$, and (ii) a peripheral annular zone bounded by two circumferences of diameters $D_{0}$ and $D_{s}$. Within the core zone, the $Z$-coordinates of datum vertices in the lower base of splat are to be taken equal to the $Z$-coordinates of the base (substrate or previously deposited coating) region corresponding to this zone because; here, the dynamic pressure of quasi liquid ensures a tight contact of the splat with the surface. In the peripheral annular zone, because of domination of radial velocity component over the substratenormal velocity component with distance from the splats core, the melt inertially spreads over the substrate surface without completely filling the cavities met in the base surface; in this way, pores are formed.

In modeling the coating cluster, we use a discretization in the form of a rectangular grid of "nodal" points in the plane 
$X Y$, with $d_{x}$ and $d_{y}$ being the discretization steps along the $X$ and $Y$-axis, respectively. The surface area of one elementary rectangle is $d S=d_{x} d_{y}$. The calculations in the splat-laying algorithm are conducted in real format. But, in the final results, the calculated $X$ - and $Y$-coordinates are then rounded to integer numbers, while $Z$-coordinates are preserved in real format.

The $Z$-coordinates of datum vertices in the annular zone are equated to the $Z$-coordinates of those vertices of the calculated trajectory for which the $Z$-coordinates of the sprayed surface turn out to be lying below the corresponding $Z$-coordinates of the calculated trajectory. Otherwise, these coordinates are to be taken equal to the corresponding $Z$ coordinates of the sprayed surface. Simultaneously, the $Z$ coordinates of the annular zone of the sprayed surface, which lie higher than the $Z$-coordinates of the calculated trajectory within thickness $h_{s}$, define the areal parts of the annular zone that remains free of the splashed melt. In other words, the effective area $S_{\text {eff }}$ of the splat contact with the substrate will be smaller than the calculated area $\pi R_{S}^{2}$ of the splat base by the sum of the areas of those contact-surface elements $(d S=$ $d_{x} d_{y}$ ) that will remain free of the splashed melt. The splatlaying algorithm is to be cyclically repeated until the total number of particles $N_{p}$ to be deposited onto the substrate is fully exhausted.

The approach to explanation of peculiarities of macroporosity formation at spreading and solidification of single quasi-liquid cermet particle, developed by us, deserves special attention. In this regard, let us assume that in an instant of time $t$ quasi-liquid cermet particle "melted metal bindersolid ultrafine carbide inclusions," spreading on the surface of the solidification front that is moving towards to it, has the appearance presented in Figure 9. As a first approximation, the surface of the solidification front at the current moment of time is represented in the form of paraboloid of revolution relative to the axis $z$; that is, its profile can be presented as $z_{s}(t, r)=z_{c}+h_{c}\left[1-\left(r / r_{c}\right)^{2}\right]$. Here $r_{c}$ is the radial coordinate of point $C$, lying outside splats core and being the contact border "particle-coating," and $h_{\mathrm{c}}$ is height of the solidified layer at $z=0$. Let us assume that immediately behind the point $O$ cavity is located on the base surface (substrate or coating) limited by the line $l$ in Figure 9. Therefore, in an instant of time $t$ there will be a separation of a quasi-liquid flow and further spreading will happen along the $\mathbf{U}_{0}$ and $\mathbf{G}_{0}$ directions with formation of pore limited in Figure 9 by the solid line $l$ and the dashed line with boundary points $C$ and $A$ (in the point $C$, the vector $\vec{G}_{0}$ is directed along the tangent to the line $C A$ ). Let us consider the reference surface $z=z_{c}+h_{0}$ crossing the section of the current frontal surface of a particle in the control point $O$. The direction of parallel vectors $\vec{G}_{0}$ and $\vec{U}_{0}$ is determined by addition of two orthogonal vectors of flow velocity components (radial $\vec{U}_{r}$ and vertical $\vec{U}_{z}$ ), taking into consideration their rotation on a small angle defined by surface curvature of the solidification front.

The tangent of this angle defines coefficient $\mu\left(r_{c}\right)$, characterizing inclination of the tangential to the surface of the solidification front in the flow separation point (Figure 9, direction $\tau$ ). This coefficient is defined by derivative

$$
\frac{d z}{d r}=-\mu\left(r_{c}\right) \equiv-\frac{2 h_{c}}{r_{c}}
$$

As a result of rotation of orthogonal vectors $\vec{U}_{r}$ and $\vec{U}_{z}$ on this angle, their directions (Figure 9) will be defined by vectors $\vec{U}_{\tau}$ and $\vec{U}_{n}$. Therefore, the trajectory of inertial motion of the separated quasi-liquid volume over cavity will be described by differential equation (with the accepted assumption about viscous spreading of quasi-liquid cermet melt in the vicinity of the stagnation point) [58]; that is, $U_{z}=-\beta \widetilde{z}^{2}, U_{r}=\beta \widetilde{z} r$, $\beta=u_{p 0} / D_{p}^{2}, \widetilde{z}=z-z_{c}+h_{0}$, and

$$
\frac{d z}{d r}=\frac{d \widetilde{z}}{d r}=\frac{U_{z}}{U_{r}}-\mu\left(r_{c}\right)=-\frac{\widetilde{z}}{r}-\mu\left(r_{c}\right) .
$$

The general solution of (10), taking account of (9) and conditions $r \geq r_{c}$, is

$$
\widetilde{z}(r)=\frac{c_{1}}{r}-\frac{\mu\left(r_{c}\right)}{2} r=c_{2} r_{c}\left(\frac{r}{r_{c}}\right)^{-1}-h_{c}\left(\frac{r}{r_{c}}\right),
$$

where $c_{1}>0$, being the arbitrary constant of the general solution, has dimension of square of the reference space scale. Therefore, it is quite natural to present it as $c_{1}=c_{2} r_{c}^{2}$. Then,

$$
z(r)=z_{c}+c_{2} r_{c}\left(\frac{r}{r_{c}}\right)^{-1}-h_{c}\left(\frac{r}{r_{c}}\right)-h_{0} .
$$

Substituting $r=r_{c}$ into (12), we will determine parameter $h_{0}$ through other parameters which are part of the solution,

$$
h_{0}=c_{2} r_{c}-h_{c}
$$

Thus, solution (12) will finally become the form

$$
z(r)=z_{c}+c_{2} r_{c}\left[\left(\frac{r}{r_{c}}\right)^{-1}-1\right]-h_{c}\left[\left(\frac{r}{r_{c}}\right)-1\right] .
$$

In the point $C$ (Figure 9), the boundary condition $z\left(r_{c}\right)=$ $z_{c}$ is automatically satisfied. At the moment of impact of a spherical quasi-liquid particle with the surface, the solidified layer is absent $\left(h_{c}=0\right)$; therefore, $\mu\left(r_{c}\right)=0$.

As it was said above, in splats core macropores are not formed owing to high dynamic pressure of normally impinging quasi-liquid flow. They are formed only in peripheral area of splat outside its core, owing to "rolling out" of the current peripheral quasi-liquid front on the base surface at which filling of surface depth shapes happens due to forward pressure, which is in proportion to $\rho_{p}\left(T_{p 0}\right) u_{p 0}^{2}$. Therefore, the free constant $c_{2}$ of the solution (14) can be presented as

$$
c_{2}=c_{0} \frac{\rho_{p}\left(T_{p 0}\right) u_{p 0}^{2}}{\rho_{p, \text { mod }}\left(T_{p, \text { mod }}\right) u_{p, \text { mod }}^{2}} .
$$

Here $c_{0}$ is the empirical constant defined as a result of parametric calculations for which macroporosity of the coating 
obtained as a result of modeling and macroporosity of the coating obtained at an actual spraying of a narrow fraction of powder at average values of particles size $D_{p \text {,mod, velocity }}$ $u_{p 0}=u_{p \text {, mod }}$, temperature $T_{p 0}=T_{p \text {, mod }}$, and base temperature $T_{b 0}=T_{b \text {, mod }}$, which are in satisfactory fit; $D_{p}$, $u_{p 0}, T_{p 0}$, and $T_{b 0}$ are values of the KPPs corresponding to calculated splat. Thus, solution (14), taking into account (15), defines the calculated trajectory of quasi-liquid enforced flow in cavities on surface of the base or sprayed coating. As appears from (15), degree of quasi-liquid flowing into cavities on the base surface significantly depends on impact velocity of cermet particle. At the same time, overheat of particle, the flowing degree, reduces owing to decrease in density of metal binder melt and, as a result, decrease in dynamic pressure. However, at high volume concentration of carbide inclusions, this decrease in density of cermet is low that can lead to slight increase in porosity of cermet coating.

Dependence of coatings macroporosity on temperature $T_{p 0}$ of sprayed particles and temperature $T_{b 0}$ of base has more complex character. Their independent or simultaneous increase leads to decrease of solidification rate of spreading quasi-liquid particles. In turn, it leads to formation of more thin splats with larger effective diameter. Thinning of splats, with other things being equal, results in decrease of characteristic dimension of asperities stochastically distributed on surface of the sprayed coating, whose relief constantly changes. It has to lead to decrease in porosity. But, at splats thinning its effective diameter increases, and, therefore, the area under peripheral ring of splat, outside its core, also increases. As appears from the foregoing analysis, at fixed velocity of quasi-liquid cermet particles colliding with base, degree of flowing of their material into different cavities at "rolling out" of the forward quasi-liquid front decreases with distance from the splats core. But, due to increase of the peripheral ring of splat, it can result in increase in effective porosity. In paper [2], the theory of cermet splats formation was developed, which allowed us to study independent influence of all KPPs on thickness and diameter of splats. It was shown that, with other things being equal, overheating of cermet particles over the melting point of binder leads to more significant, in comparison with increase in their velocity, increase in their spreading factor and, therefore, the area under splats peripheral ring.

Unfortunately, at present there are no systematic experimental data characterizing porosity of thermally sprayed cermet coatings depending on temperature of sprayed particles at the fixed values of other key physical parameters (size and velocity of particles and substrate temperature) at high volume concentration of carbide inclusions. However, as first approximation, it is possible to use the results of work [62] in which HVOF spraying experiments were conducted. For all experiments, an agglomerated and sintered WC-12\% Co powder of type WOKA 3102 from Sulzer Metco was used. The particles size of $-45+15 \mu \mathrm{m}$ was determined by laser scattering and sieve analysis by Sulzer Metco. The in-flight particles behavior was studied using an optical diagnostic system, while coating properties, in particular coatings porosity, were analyzed by metallographic methods.
In paper [62], it was obtained, in particular, that at effective values of particles velocity $u_{p 0}=843 \mathrm{~m} / \mathrm{s}$, temperature $T_{p 0}=2034 \mathrm{~K}$, and coating thickness $h=351 \mu \mathrm{m}$, the value of porosity was equal to $2.2 \%$. At the same time, at $u_{p 0}=$ $839 \mathrm{~m} / \mathrm{s}, T_{p 0}=2066 \mathrm{~K}$, and $h=352 \mu \mathrm{m}$, the value of porosity was equal to $2.8 \%$. It qualitatively is in agreement with the results of modeling presented below, which also illustrate, with other things being equal, increase in porosity with increase in particles temperature at modeling of TiC-30 vol.\% $\mathrm{NiCr}$ coatings sprayed on steel substrate.

As additional confirmation of increase in porosity of plasma-sprayed coatings at increase in temperature of particles are the results obtained in paper [63]. The authors of this paper focused their attention on the use of hydrogen and nitrogen as secondary gases for atmospheric plasma spray using the TriplexPro-210 gun. In particular, they have carried out the comparison of coatings porosity at plasma spraying of Amdry $960(\mathrm{NiCr}) 6 \mathrm{Al}$ powder (fraction $-125+37 \mu \mathrm{m})$. At particles temperature $T_{p 0}=2775 \pm 125^{\circ} \mathrm{C}$ and velocity $u_{p 0}$ $=125 \pm 25 \mathrm{~m} / \mathrm{s}$, the measured porosity was of $P=0.8 \%$. At the same time, the porosity of $P=1.1 \%$ was obtained at particles temperature $T_{p 0}=2850 \pm 101^{\circ} \mathrm{C}$ and velocity $u_{p 0}=$ $132 \pm 26 \mathrm{~m} / \mathrm{s}$.

However, more reliable verification of the computational technology developed by us requires conduction of specific model physical experiments that is a subject of follow-up study.

\section{Some Results on Cermet Coatings Simulation}

All calculations were carried out with use of laptop with the following characteristics: Intel i7-4710MQ processor, clock frequency $2.5 \mathrm{GHz}, 8 \mathrm{~GB}$ RAM, $240 \mathrm{~Gb}$ SSD Kingston SV300S37A240G (450 Mb/s), and operational system Windows 7.

In the course of modeling of the coating building-up, information is recorded on the hard disk in parts, as $2 \mathrm{~GB}$ RAM is not enough for storage of all working arrays in which information on coating is stored. Taking into account the above, effective time spent for laying one cermet splat is $160 \mathrm{~ms}$ including the time of exchange with the hard disk.

Calculation of coatings cluster of the size $2 \mathrm{~mm} \times 2 \mathrm{~mm} \times$ $200 \mu \mathrm{m}$ (space resolution of $d_{x}=d_{y}=1 \mu \mathrm{m}$ ) at modeling of process of TiC-30 vol.\% NiCr powder spraying $\left(D_{p}=40 \mu \mathrm{m}\right.$, $u_{p 0}=200 \mathrm{~m} / \mathrm{s}, T_{p 0}=2000 \mathrm{~K}$, and $T_{b 0}=400 \mathrm{~K}$ ) demands the laying of 16340 splats. Therefore, the total time of calculation of the coatings cluster will be $\sim 44 \mathrm{~min}$.

Extrapolation of resulting time on modeling larger coatings cluster allows to estimate the required computing time. But, as the data presented in Figure 10(a) show, often it is not necessary to carry out the modeling of larger cluster. It needs to be done if values of KPPs are not spatially uniform in the cross section of spraying spot. But, in this case, it is reasonable to scan the spraying spot, carrying out modeling of coating clusters, which basis sizes are, for example, $2 \mathrm{~mm} \times 2 \mathrm{~mm}$ or a little more. As appears from the data presented in Figure 10(a), in this case it is possible 


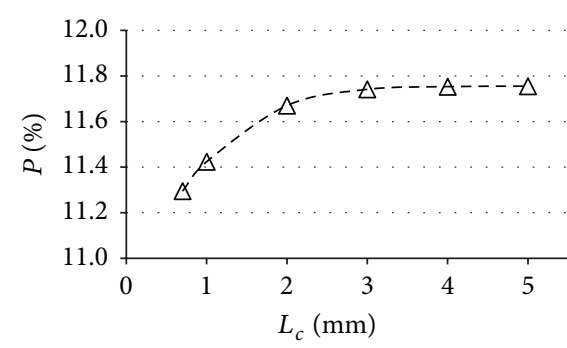

(a)

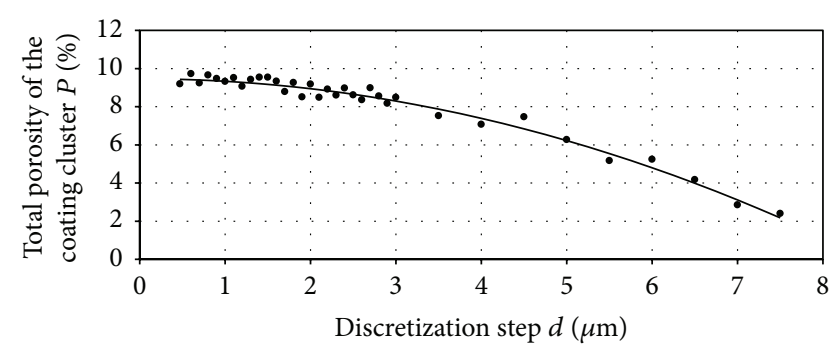

(b)

Figure 10: Porosity of the TiC-30 vol.\% NiCr coating cluster on steel substrate versus characteristic size $L_{c}$ of cluster at the following spraying conditions $D_{p}=40 \mu \mathrm{m}, u_{p 0}=200 \mathrm{~m} / \mathrm{s}, T_{p 0}=2000 \mathrm{~K}$, and $T_{b 0}=400 \mathrm{~K}$ (a) and versus step $d$ of discretization in the substrate plane $\left(d=d_{x}=\right.$ $\left.d_{y}\right)(\mathrm{b})$.

to provide statistically reliable estimations of the coating characteristics, for instance, macroporosity. The computing experiments, carried out earlier and presented in paper [28], have enabled the determination of the total effective porosity to depend on the discretization step $d$ (Figure 10(b)), which made it possible to introduce a relative correction for the porosity value depending on the discretization step (at $d<$ $1 \mu \mathrm{m}$, the porosity, under the same remaining conditions, did not practically change). For this case, the size of the copper substrate was $2 \times 2 \mathrm{~mm}\left(T_{b 0}=300 \mathrm{~K}\right)$. The sizes of sprayed particles (nickel) $D_{p}=20-40 \mu \mathrm{m}$, the velocity $u_{p 0}=120 \mathrm{~m} / \mathrm{s}$, and the temperature $T_{p 0}=2000 \mathrm{~K}$. The number of particles sprayed was 10000 .

The cermet powders of WC-Me $(\mathrm{Me}=\mathrm{Co}, \mathrm{Co}-\mathrm{Cr})$ became widespread at thermal spraying of wear-, abrasive-, and corrosion-resistant coatings. These powders are characterized by high volume content of ultrafine carbide inclusions (up to 90\%), which are uniformly distributed in the Co or Co-Cr matrix. At present, various high velocity oxyfuel (HVOF) systems are used at spraying of these powders. As a rule, temperature of WC-Me composite particles at HVOF does not greatly exceed the melting point of metal binder, and their residence time in high-temperature jet under spraying equals $\sim 1 \mathrm{~ms}$. The degree of dissolution and decarburization of ultrafine inclusions of WC in binder melt thus are significantly lesser in comparison with the data predicted by the equilibrium diagram. But, use of plasma spraying of such powders is rather problematic due to more intensive tungsten carbide degradation $\mathrm{WC} \rightarrow \mathrm{W}_{2} \mathrm{C} \rightarrow \mathrm{W}$ at higher temperatures [64].

The new opportunities which are available when using tungstenless nano- and submicrometer structured cermet powders of $\mathrm{TiC}-\mathrm{NiCr}$ for thermal as well as plasma spraying of wear-, abrasive-, and corrosion-resistant coatings [65]. In this paper, the combined method of $\mathrm{TiC}-\mathrm{NiCr}$ cermet powders production with particle size of $40-90 \mu \mathrm{m}$ and preset volume content (50-85\%) of ultrafine carbide inclusions was proposed. The method is based on combination of (i) preliminary high-energy (acceleration $\sim 100 \mathrm{~g}$ ) mechanoactivation of initial $\mathrm{Ti}$ and NiCr powder components; (ii) subsequent self-propagating high-temperature synthesis (SHS) carried out in a free combustion mode in a powder mixture $\mathrm{Ti}-\mathrm{C}-$ $\mathrm{NiCr}$; and (iii) sieving the final powder product obtained by grinding the synthesized cermet compact. The X-ray analysis of samples of the powder products confirmed the presence of only titanium carbide and nickel-chrome alloy phases.

Taking into account that (1) SHS of solid ultrafine particles of titanium carbide in $\mathrm{Ti}-\mathrm{C}-\mathrm{NiCr}$ powder composition is realized in $\mathrm{NiCr}$ melt during several milliseconds (i.e., comparable with the residence time of composite $\mathrm{TiC}-\mathrm{NiCr}$ particles in high-temperature flow at spraying of coatings) and (2) as a result of the X-ray analysis of the synthesized cermet powder, it could not be found of any meaningful quantity of other phases, with the exception of titanium carbide and nickel-chrome alloy, it is possible to draw the conclusion that the synthesized cermet powder, in particular, $\mathrm{TiC}-30$ vol.\% NiCr powder, can find the application for thermal spraying of wear-, abrasive-, and corrosion-resistant coatings.

Let us analyze the results of calculations carried out at TiC-30 vol.\% NiCr coatings formation with the use of developed physical and theoretical bases, computing algorithms and program code. In this regard, we note that calculations of single $\mathrm{TiC}-\mathrm{NiCr}$ splats formation on steel substrate at independent alteration of KPPs in range of values that are of interest for plasma, detonation, and HVOF spraying are presented in paper [2]. Necessary thermophysical properties of materials are also given there.

The numerical analysis of behavior of porosity of the TiC30 vol.\% NiCr powder coatings at independent variation of KPPs, velocities, size, and temperature of powder particles as well as substrates temperature (Figures 11-14), is of special interest. In all calculations, the thickness of coatings was $200 \mu \mathrm{m}$, dimensions of coatings cluster were $2 \times 2 \mathrm{~mm}$, and resolution was $d_{x}=d_{y}=1 \mu \mathrm{m}$.

As it can be seen from results of calculations, velocity of particles is the most significant parameter, which affects macroporosity of cermet coatings: alteration of particles velocity from 200 to $600 \mathrm{~m} / \mathrm{s}$ leads to reduction of coatings porosity by three times. It is caused by the fact that with increase of quasi-liquid particles velocity the relative diameter of area under each splat, completely filled with its material, increases. As it was shown above, degree of quasiliquid flowing into cavities on the base surface significantly depends on impact velocity of cermet particle. The estimated values of macroporosity of the coatings clusters $P \sim 12 \%$ and 


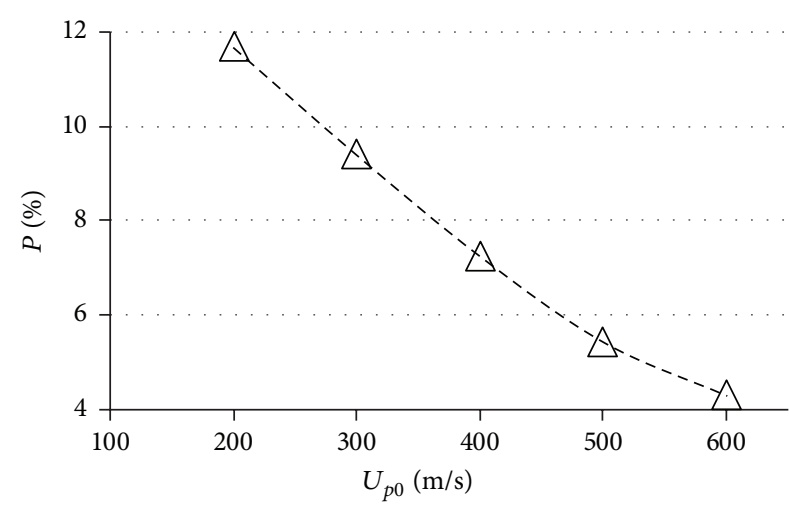

Figure 11: Porosity of coatings versus velocity of particles. $D_{p}=$ $40 \mu \mathrm{m}, T_{p 0}=2000 \mathrm{~K}$, and $T_{b 0}=400 \mathrm{~K}$.

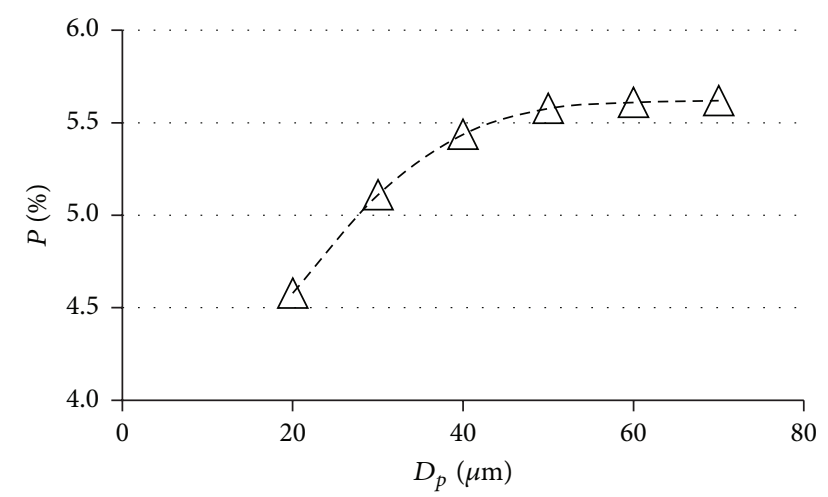

Figure 12: Porosity of coatings versus diameter of particles. $u_{p 0}=$ $500 \mathrm{~m} / \mathrm{s}, T_{p 0}=2000 \mathrm{~K}$, and $T_{b 0}=400 \mathrm{~K}$.

$P \sim 4 \%$ at particles velocities $200 \mathrm{~m} / \mathrm{s}$ (APS) and $600 \mathrm{~m} / \mathrm{s}$ (HVOF) agree satisfactorily with our experimental data.

It is interesting to note the increase of coatings macroporosity at independent increase of particle diameter and particle temperature, as well as substrate temperature, with other things being equal, close to conditions realized at detonation and HVOF spraying (Figures 11-14). As it was shown in [2], with all other things being equal, overheating of cermet particles above the melting point of binder leads to more significant, in comparison with increase in their velocity, increase in their spreading factor and, therefore, increase in area under splats peripheral ring. It, in turn, results in increase in effective porosity.

\section{Conclusions}

(1) The approach to modeling the process of the formation of a lamellar structure of thermal sprayed coatings, including the plasma coatings at the spraying of cermet powders, which was considered in the present paper, and the assessment of their structural and functional characteristics enable one, in a first approximation, to purposefully design and optimize the coatings with the properties needed for practice.

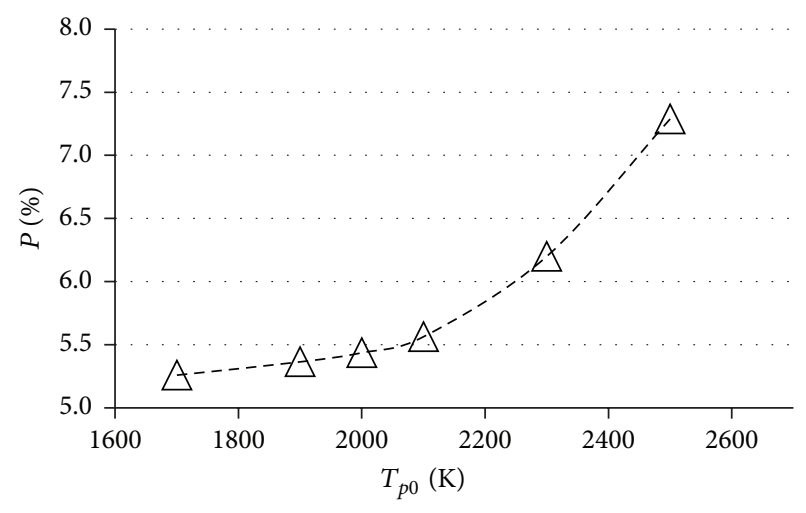

FIGURE 13: Porosity of coatings versus temperature of particles. $D_{p}=$ $40 \mu \mathrm{m}, u_{p 0}=500 \mathrm{~m} / \mathrm{s}$, and $T_{b 0}=400 \mathrm{~K}$.

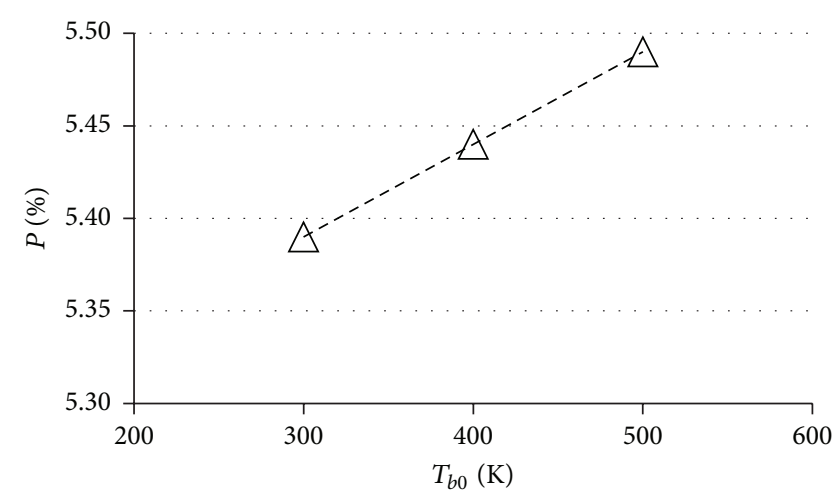

FIgURE 14: Porosity of coatings versus substrate temperature. $D_{p}=$ $40 \mu \mathrm{m}, u_{p 0}=500 \mathrm{~m} / \mathrm{s}$, and $T_{p 0}=2000 \mathrm{~K}$.

(2) Effective algorithm of computer simulation of consecutive stochastic laying of splats on the surface with variable relief, changeable while modeling the coating formation, was developed.

(3) Problem-oriented program code, based on approach and algorithms developed, was created, which allows carrying out the computer experiments with the aim of (i) selection of KPPs for producing cermet splats with given characteristics, (ii) stochastic modeling of formation of cermet coatings lamellar structure for given distributions of KPPs in cross-section of spraying spot versus the concentration of solid inclusions suspended in the metal-binder melt, and (iii) calculation of functional characteristics of coatings, obtained as a result of their modeling in $2 \mathrm{D}$ and $3 \mathrm{D}$ graphics.

\section{Conflict of Interests}

The authors declare that there is no conflict of interests regarding the publication of this paper.

\section{Acknowledgments}

The results presented have been obtained in the framework of Program of Fundamental Investigations of the Russian 
Academy of Sciences on 2013-2020. The authors express thanks to Mr. Kirill Solonenko for his help on preparing of English version of the paper presented.

\section{References}

[1] O. P. Solonenko, V. E. Ovcharenko, Y. F. Ivanov, and A. A. Golovin, "Plasma-sprayed metal-ceramic coatings and modification of their structure with pulsed electron-beam irradiation," Journal of Thermal Spray Technology, vol. 20, no. 4, pp. 927-938, 2011.

[2] O. P. Solonenko, "Formation of splats from suspension particles with solid inclusions finely dispersed in a melted metal matrix," Journal of Thermal Spray Technology, vol. 21, no. 6, pp. 1135-1147, 2012.

[3] V. V. Kudinov, Plasma Coatings, Nauka, Moscow, Russia, 1997 (Russian).

[4] G. Trapaga, E. F. Matthys, J. J. Valencia, and J. Szekely, "Fluid flow, heat transfer, and solidification of molten metal droplets impinging on substrates: Comparison of numerical and experimental results," Metallurgical Transactions B, vol. 23, no. 6, pp. 701-718, 1992.

[5] H. Maruo, Y. Hirata, and Y. Matsumoto, "Deformation and solidification of a molten droplet by impact on a planar substrate," in Proceedings of the 14th International Thermal Spray Conference, vol. 1, pp. 341-346, Kobe, Japan, 1995.

[6] M. Bertagnolli, M. Marchese, and G. Jacucci, "Modeling of particles impacting on a rigid substrate under plasma spraying conditions," Journal of Thermal Spray Technology, vol. 4, no. 1, pp. 41-49, 1995.

[7] M. Bussmann, S. Chandra, and J. Mostaghimi, "Modeling the splash of a droplet impacting a solid surface," Physics of Fluids, vol. 12, no. 12, pp. 3121-3132, 2000.

[8] A. Ilyuschenko, A. Lakubenya, G. Gromyko, and G. Zayats, "Mathematical modeling of deformation and solidification of molten droplet on a flat substrate in a plasma spray process," in Proceedings of the 2nd International Thermal Spray Conference (ITSC '01), pp. 959-966, Singapore, May 2001.

[9] J. Mostaghimi and S. Chandra, "Splat formation in plasma-spray coating process," Pure and Applied Chemistry, vol. 74, no. 3, pp. 441-445, 2002.

[10] M. Raessi, J. Mostaghimi, and M. Bussmann, "Droplet impact during the plasma spray coating process-effect of surface roughness on splat shapes," in Proceedings of the 17th International Symposium on Plasma Chemistry, pp. 916-917, Toronto, Canada, August 2005.

[11] H. Liu, S. Krishnan, S. Marella, and H. S. Udaykumar, "Sharp interface Cartesian grid method II: a technique for simulating droplet interactions with surfaces of arbitrary shape," Journal of Computational Physics, vol. 210, no. 1, pp. 32-54, 2005.

[12] E. Lugscheider, K. Bobzin, and R. Nickel, "Application of multiscale modeling in the coating formation simulation of APS-PYSZ-TBCs," in Proceedings of the International Thermal Spray Conference (ITSC '06), pp. 537-544, Seattle, Wash, USA, May 2006.

[13] H. B. Parizi, L. Rosenzweig, J. Mostaghimi et al., "Numerical simulation of droplet impact on patterned surfaces," in Proceedings of the International Thermal Spray Conference, pp. 213-218, 2007.
[14] S. Chandra and P. Fauchais, "Formation of solid splats during thermal spray deposition," Journal of Thermal Spray Technology, vol. 18, no. 2, pp. 148-180, 2009.

[15] O. Knotek and R. Elsing, "Monte Carlo simulation of the lamellar structure of thermally sprayed coatings," Surface \& Coatings Technology, vol. 32, no. 1-4, pp. 261-271, 1987.

[16] S. Cirolini, J. H. Harding, and G. Jacucci, "Computer simulation of plasma-sprayed coatings I. Coating deposition model," Surface and Coatings Technology, vol. 48, no. 2, pp. 137-145, 1991.

[17] V. A. Klimenov, S. I. Negressul, O. P. Solonenko, and S. A. Ostapenko, Computer Modeling of Particles Laying at Thermal Spraying, ISPM SB RAS, Tomsk, Russia, 1993 (Russian).

[18] H. Fukanuma, "Porosity formation and flattening model of an impinging molten particle in thermal spray coatings," Journal of Thermal Spray Technology, vol. 3, no. 1, pp. 33-44, 1994.

[19] S. Cirolini, M. Marchese, J. H. Harding, and P. A. Mulheran, "Modeling the microstructure of thermal barrier coatings," Materials and Design Technology, vol. 162, pp. 189-198, 1994.

[20] S. Das, V. K. Suri, U. Chandra, and K. Sampath, "Onedimensional mathematical model for selecting plasma spray process parameters," Journal of Thermal Spray Technology, vol. 4, no. 2, pp. 153-162, 1995.

[21] S. P. Kundas, A. P. Dostanko, A. F. Ilyushchenko, A. N. Kuz'menkov, E. Lugscheider, and U. Eritt, Computer Modeling of Processes of Coatings Plasma Spraying, Bestprint, Minsk, Belarus, 1998, (Russian).

[22] M. P. Kanouff, R. A. Neiser Jr., and T. J. Roemer, "Surface roughness of thermal spray coating made with off-normal spray angle," Journal of Thermal Spray Technology, vol. 7, no. 2, pp. 219228, 1998.

[23] R. Ghafouri-Azar, J. Mostaghimi, and S. Chandra, "Deposition model of thermal spray coatings," in Proceedings of the 2nd International Thermal Spray Conference (ITSC '01), pp. 951-958, Singapore, May 2001.

[24] R. Ghafouri-Azar, J. Mostaghimi, S. Chandra, and M. Charmchi, "A stochastic model to simulate the formation of a thermal spray coating," Journal of Thermal Spray Technology, vol. 12, no. 1, pp. 53-69, 2003.

[25] V. I. Kalita and A. G. Gnedovets, "Plasma spraying of capillary porous coatings: experiments, modeling, and biomedical applications," Plasma Processes \& Polymers, vol. 2, no. 6, pp. 485-492, 2005.

[26] T. Steinke and M. Baker, "Monte Carlo simulation of thermal sprayed coatings," in Proceedings of the International Thermal Spray Conference, pp. 329-334, Seattle, Wash, USA, May 2006.

[27] K. Bobzin, N. Bagcivan, D. Parkot, M. Schäfer, and I. Petković, "Modeling and simulation of microstructure formation for porosity prediction in thermal barrier coatings under air plasma spraying condition," Journal of Thermal Spray Technology, vol. 18, no. 5-6, pp. 975-980, 2009.

[28] O. P. Solonenko, V. A. Blednov, and V. I. Iordan, "Computer design of thermal sprayed metal powder coatings," Thermophysics \& Aeromechanics, vol. 18, no. 2, pp. 255-272, 2011.

[29] J. Madejski, "Solidification of droplets on a cold surface," International Journal of Heat and Mass Transfer, vol. 19, no. 9, pp. 1009-1013, 1976.

[30] H. Liu, E. J. Lavernia, and R. H. Rangel, "Numerical simulation of impingement of molten $\mathrm{Ti}, \mathrm{Ni}$ and $\mathrm{W}$ droplets on flat substrate," Journal of Thermal Spray Technology, vol. 2, pp. 369378, 1993. 
[31] G. Trapaga and J. Szekely, "Mathematical modeling of the isothermal impingement of liquid droplets in spraying processes," Metallurgical Transactions B, vol. 22, no. 6, pp. 901-914, 1991.

[32] M. Bertagnolli, M. Marchese, G. Jacucci, I. St. Doltsinis, and S. Noelting, "Thermomechanical simulation of the splashing of ceramic droplets on a rigid substrate," Journal of Computational Physics, vol. 133, no. 2, pp. 205-221, 1997.

[33] T. Yoshida, "Development of an integrated fabrication process for solid oxide fuel cells by using novel plasma spraying," in Energy Conversation and Utilization with High Efficiency, C: Science and Technology for Energy Conversation, CO1-17, pp. 99$104,1990$.

[34] T. Watanabe, I. Kuribayashi, T. Honda, and A. Kanzawa, "Deformation and solidification of a droplet on a cold substrate," Chemical Engineering Science, vol. 47, no. 12, pp. 3059-3065, 1992.

[35] G. Montavon and C. Coddet, "Heuristic modelling of thermally sprayed powder splat characteristics," in Proceedings of the 8th National Thermal Spray Conference, pp. 225-230, Houston, Tex, USA, September 1995.

[36] H. Jones, "Cooling, freezing and substrate impact of droplets formed by rotary atomization," Journal of Physics D: Applied Physics, vol. 4, no. 11, pp. 1657-1660, 1971.

[37] D. A. Gasin and B. A. Uryukov, "Dynamics of a liquid particle interaction with substrate," Izvestiya of SB Academy of Science USSR, Series Technical Science, vol. 3, no. 6, pp. 95-100, 1986 (Russian).

[38] S. Chandra and C. T. Avedisian, "On the collision of a droplet with a solid surface," Proceedings of the Royal Society of London. Series A, vol. 432, p. 13, 1991.

[39] M. Pasandideh-Fard, Y. M. Qiao, S. Chandra, and J. Mostaghimi, "Capillary effects during droplet impact on a solid surface," Physics of Fluids, vol. 8, no. 3, pp. 650-659, 1996.

[40] M. Kurokawa and S. Toda, "Heat transfer of an impacted single droplet on the wall," in Proceedings of the ASME-JSME Thermal Engineering Joint Conference, vol. 2, pp. 141-146, 1991.

[41] L. Cheng, "Dynamic spreading of drops impacting onto a solid surface," Industrial \& Engineering Chemistry Process Design and Development, vol. 16, no. 2, pp. 192-197, 1977.

[42] E. W. Collings, A. J. Markworth, J. K. McCoy, and J. H. Saunders, "Splat-quench solidification of freely falling liquid-metal drops by impact on a planar substrate," Journal of Materials Science, vol. 25, no. 8, pp. 3677-3682, 1990.

[43] C.-J. Li, H.-L. Liao, P. Gougeon, G. Montavon, and C. Coddet, "Experimental determination of the relationship between flattening degree and Reynolds number for spray molten droplets," Surface and Coatings Technology, vol. 191, no. 2-3, pp. 375-383, 2005.

[44] O. P. Solonenko, "State-of-the art of thermophysical fundamentals of plasma spraying," in Thermal Plasma and New Materials Technology, O. P. Solonenko and M. F. Zhukov, Eds., vol. 2, pp. 7-96, Cambridge International Science Publishing, Cambridge, UK, 1995.

[45] O. P. Solonenko, V. V. Kudinov, A. V. Smirnov et al., "Micrometallurgy of splats: theory, computer simulation and experiment," JSME International Journal, Series B: Fluids and Thermal Engineering, vol. 48, no. 3, pp. 366-380, 2006.

[46] V. V. Sobolev and J. M. Guilemany, "Flattening of droplets and formation of splats in thermal spraying: a review of recent work, part 1," Journal of Thermal Spray Technology, vol. 8, pp. 87-101, 1999.
[47] V. V. Sobolev and J. M. Guilemany, "Flattening of droplets and formation of splats in thermal spraying: a review of recent work. Part 2," Journal of Thermal Spray Technology, vol. 8, no. 2, pp. 301-304, 1999.

[48] S. D. Aziz and S. Chandra, "Impact, recoil and splashing of molten metal droplets," International Journal of Heat and Mass Transfer, vol. 43, no. 16, pp. 2841-2857, 2000.

[49] S. Q. Armster, J.-P. Delplanque, M. Rein, and E. J. Lavernia, "Thermo-fluid mechanisms controlling droplet based materials processes," International Materials Reviews, vol. 47, no. 6, pp. 265-301, 2002.

[50] J. Mostaghimi, M. Pasandideh-Fard, and S. Chandra, "Dynamics of splat formation in plasma spray coating process," Plasma Chemistry \& Plasma Processing, vol. 22, no. 1, pp. 59-84, 2002.

[51] C. Escure, M. Vardelle, and P. Fauchais, "Experimental and theoretical study of the impact of alumina droplets on cold and hot substrates," Plasma Chemistry \& Plasma Processing, vol. 23, no. 2, pp. 185-221, 2003.

[52] P. Fauchais, M. Fukumoto, A. Vardelle, and M. Vardelle, "Knowledge concerning splat formation: an invited review," Journal of Thermal Spray Technology, vol. 13, no. 3, pp. 337-360, 2004.

[53] P. Fauchais, "Understanding plasma spraying," Journal of Physics D: Applied Physics, vol. 37, no. 9, pp. R86-R108, 2004.

[54] A. McDonald, S. Chandra, and C. Moreau, "Photographing impact of plasma-sprayed particles on rough substrates," Journal of Materials Science, vol. 43, no. 13, pp. 4631-4643, 2008.

[55] O. P. Solonenko, "Spreading and solidification of a metal droplet with a high volume concentration of solid refractory inclusions on a substrate," Technical Physics Letters, vol. 38, no. 1, pp. 17-21, 2012.

[56] V. V. Sobolev and J. M. Guilemany, "Formation of splats during thermal spraying of composite powder particles," Materials Letters, vol. 42, no. 1, pp. 46-51, 2000.

[57] C.-J. Li, Y.-Y. Wang, G.-J. Yang, A. Ohmori, and K. A. Khor, "Effect of solid carbide particle size on deposition behaviour, microstructure and wear performance of HVOF cermet coatings," Materials Science and Technology, vol. 20, no. 9, pp. 10871096, 2004.

[58] H. Schlichting, Grenzschicht-Teorie, G. Braun, Karlsruhe, Germany, 1964.

[59] A. D. Panasyuk, V. S. Fomenko, and G. G. Glebova, Resistance of Nonmetallic Materials in Melt. Handbook, Naukova Dumka, Kiev, Ukraine, 1986 (Russian).

[60] O. P. Solonenko, "Sensitivity analysis and inverse link 'outlet coating characteristics torch operating conditions' in thermal spray technology," in Proceedings of the 14th International Symposium on Plasma Chemistry, vol. 4, pp. 1995-2000, Prague, Czech Republic, August 1999.

[61] E. V. Shikin and A. I. Plis, Curves and Surfaces on the Monitor Screen, Manual on Splines for the User, Dialog-MIFI, Moscow, Russia, 1996 (Russian).

[62] W. Tillmann, E. Vogli, B. Hussong, S. Kuhnt, and N. Rudak, "Relations between in flight particle characteristics and coating properties by HVOF-spraying," in Proceedings of the Thermal Spray: Global Solutions for Future Application (ITSC '10), Singapore, May 2010.

[63] D. Chen, J. Colmenares-Angulo, R. Molz, C. Dambra, and D. Hawley, "Helium-free parameter development for TriplexPro210 plasma gun," in Proceedings of the Intelligent Transportation 
Systems Conference (ITSC '11), pp. 649-654, Hamburg, Germany, September 2011.

[64] A. Koutsomichalis, N. Vaxevanidis, G. Petropoulos, E. Xatzaki, A. Mourlas, and S. Antoniou, "Tribological coatings for aerospace applications and the case of WC-Co plasma spray coatings," Tribology in Industry, vol. 31, no. 1-2, pp. 37-42, 2009.

[65] O. P. Solonenko, A. E. Chesnokov, and A. V. Smirnov, "Production and plasma spraying of cermet powders $\mathrm{TiC}-\mathrm{NiCr}$ with given volume content of carbide ultra-fine inclusions," in Proceedings of the International Thermal Spray Conference (ITSC '14), pp. 373-378, Barcelona, Spain, May 2014. 

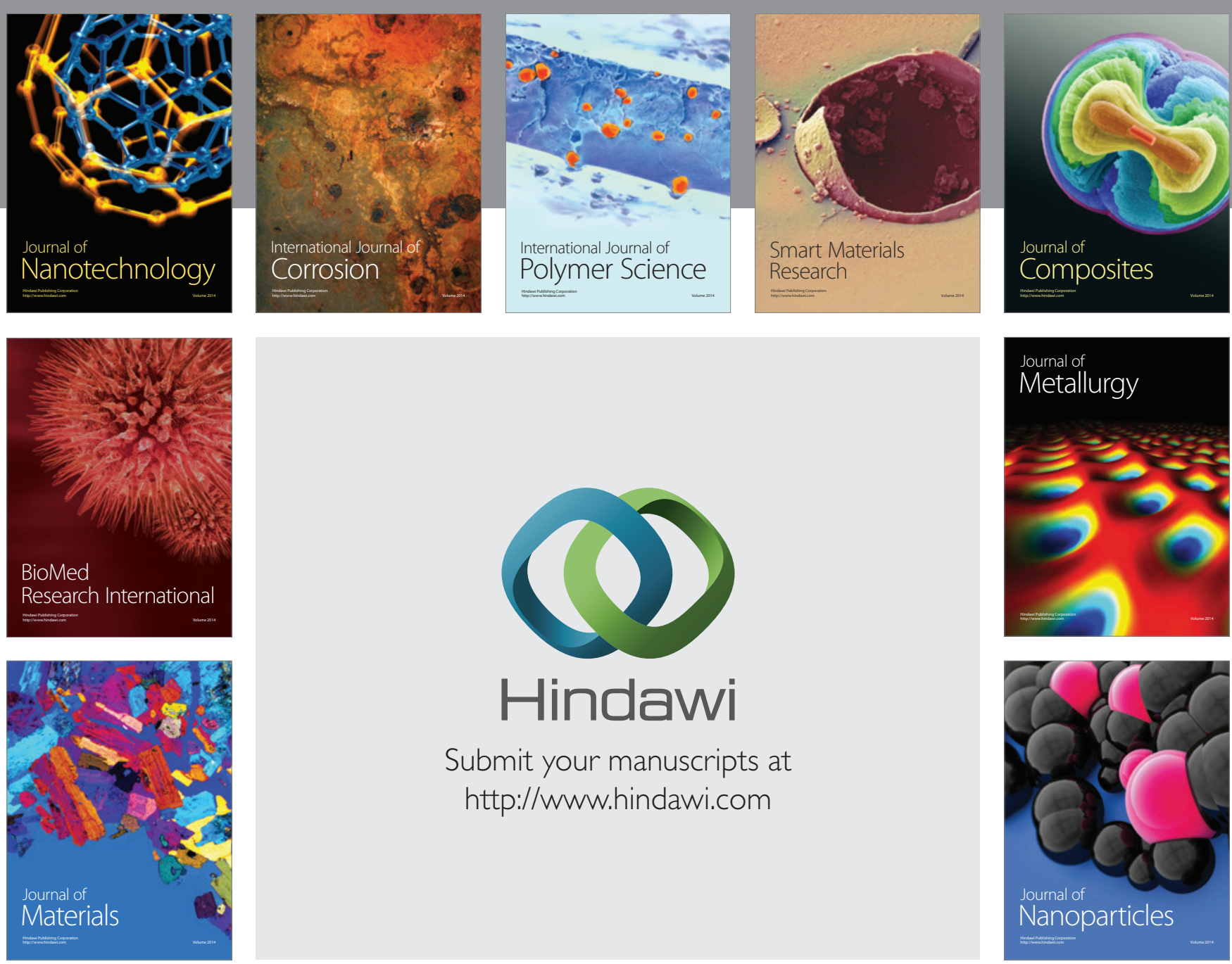

Submit your manuscripts at http://www.hindawi.com
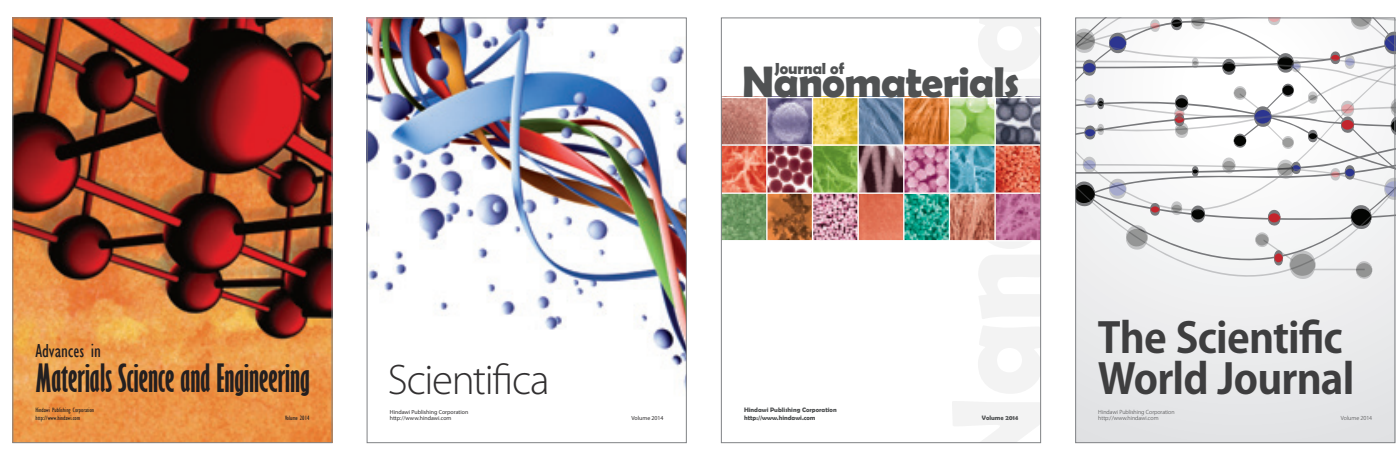

\section{The Scientific World Journal}
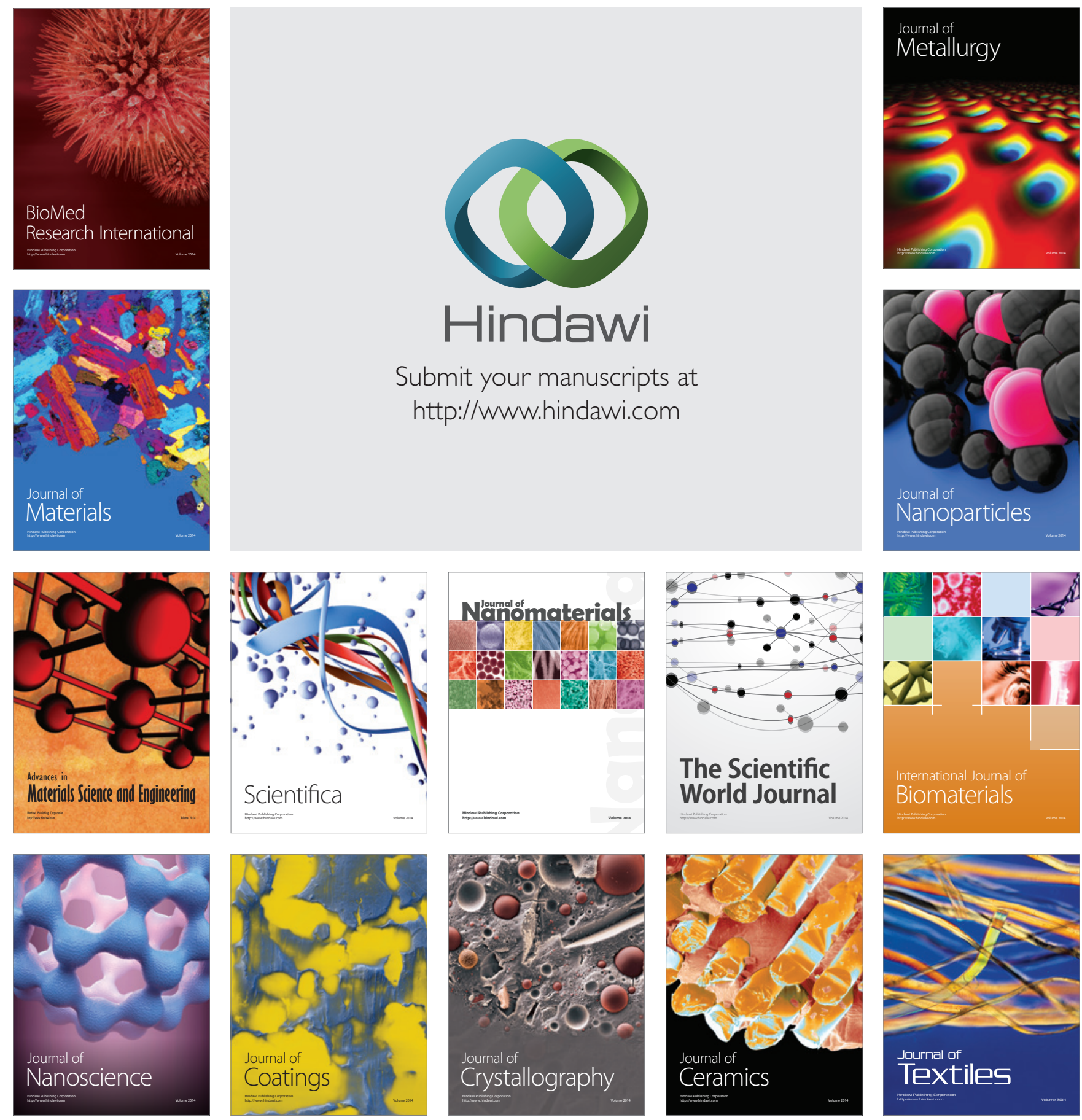